\title{
Competing motivations in the diachronic nominalization of English gerunds
}

\section{Abstract}

The present study is an in-depth, corpus-based analysis of the rise and institutionalization of the indefinite nominal gerund in Late Modern English, considering the observed developments in light of their interactions with neighboring constructions in the language network. Based on historical data taken from the Corpus of Late Modern English Texts (version 3.1), we argue that the rise of indefinite nominal gerunds constitutes an instance of diachronic nominalization, in which the nominal gerund over time gradually comes to exploit a fuller range of paradigmatic properties associated with the nominal class. At the same time, this study investigates the potential influence of isomorphism on the observed developments. While the results do support the frequently investigated claim that language systems have a (weak) preference for a one-form-one-meaning organization in later stages of the development, the initial emergence of indefinite nominal gerunds can more accurately be explained by allowing system pressure as an enabling force of linguistic innovation. The picture presented in this study serves as evidence that the long-term development of linguistic constructions can be the result of competing - even maximally opposite - forces.

\section{Introduction}

The history of the English gerund is perhaps most notably characterized by the gradual development of a structurally verbal component, which resulted in an elaborate gerundive nominalization system that consists of a cline or 'squish' from more noun phrase-like to more non-finite clause-like structures (Ross 1973; Quirk et al. 1985: 1290-1291). ${ }^{1}$ The morphosyntactic verbalization of the English gerund has been addressed quite extensively in the diachronic literature (Jespersen 1946: 108-150; Einenkel 1914; Mustanoja 1960: 566-578; Visser 1973: 1165-1217; Emonds 1973; Tajima 1985, 1996, 1999; Donner 1986; Jack 1988; Houston 1989; Van der Wurff 1993; Fanego 1996, 1998, 2004; Miller 2002; Kranich 2006, 2007; Zehentner 2014), leaving us with a relatively clear picture of

\footnotetext{
1 The gerundive squish can, in turn, be placed on a more general (cross-linguistically attested) continuum between action nominals and nominalized clauses (Comrie 1976; Comrie \& Thompson 1985; KoptjevskajaTamm 1993), with nominal gerunds being situated closest to the action nominal end of the cline and verbal gerunds taking a more intermediate position (cf. their respective positions on Ross's nouniness squish, see Section 3.2.2; De Smet 2008: 56; Lees 1966; Langacker 1991; Heyvaert 2003, 2004).
} 
the gradual reconfiguration of noun phrase structure into non-finite clause structure. In Old English, the derivational mechanism -ing $(g)(e)$ or - $u n g(g)(e)$ created abstract nouns from verbal stems. These Old English 'gerunds' were, in terms of their morphosyntactic behavior, entirely nominal, taking nominal dependents such as determiners, genitive phrases, and adjectives (Fanego 2004: 7; De Smet 2008: 61-64).

(1) đurh đæra sacerda blawunge toburston đa weallas

(Visser 1973: 1165)

'Through the blowing of the priests the walls burst'

In Middle English, the -ung $(g)(e)$ ending gradually disappeared, which made -ing the sole mechanism for forming these deverbal abstract nouns (Kisbye 1971: 54; Dalton-Puffer 1996: 90-91; Miller 2002: 315-321). Moreover, as the case system disappeared, the genitive phrase that was previously used to express the object was replaced by a periphrastic of-phrase (Mustanoja 1960: 74-76; Tajima 1985: 60ff.), as in (2):

(2) Withouten doying of any harme (Tajima 1985: 62)

Up until the Late Middle English period, these deverbal nouns in -ing $(g)(e)$ behave "nicely within the syntactical boundaries of a noun" (Kisbye 1971: 55). Around 1300, however, they started showing the first signs of clausal syntax (Tajima 1985: 111-113; Fischer 1992: 252). These newly formed verbal gerunds (e.g. filching hens [1552-1563]), while fairly uncommon and infrequent in Middle English, grew increasingly popular in the Early Modern period (De Smet 2008; Fanego 2004).2

Yet, while the emergence and rise of the verbalized gerund is perhaps the most eye-catching morphosyntactic development in the English gerundive system, the nominal gerund also underwent a structural change that has thus far been overlooked. This change consists in a remarkable rise of nominal gerunds that combine with an indefinite article, as in (3):

(3) a. As he shut the pages a creaking of the wicker chair again attracted his attention. (1896, CLMET3.1)

b. My compliment, or insinuation, produced a pleased smile and a gallant twirling of his moustache. (1894, CLMET3.1)

\footnotetext{
${ }^{2}$ As the verbal gerund gained in frequency, it also acquired a number of additional 'verbal' features, such as the ability to distinguish voice (Mustanoja 1960: 573), as in (a), and secondary tense, as in (b):

(a) He is so subtill and full of all craft and fleight, that no earthly creature can escape from being seduced by him. (1593, PPCEME)

(b) And craving also pardon for hauing troubled yor honor wth so tedious a letter I most humbly take my leaue ffrom [sic.] Paris the second of Januarie 1598. (1599, PPCEME)

The final 'clausal' innovation in the internal structure of the verbal gerund is illustrated by an example such as (c), where the subject of the gerund is expressed in the oblique rather than the genitive case:

(c) For the rest, dear Mother, be not concerned about my health suffering. (1835, PPCMBE)
} 
These indefinite nominal gerunds are formally characterized in that they derive a nominal form from a verbal stem (e.g. to creak, to twirl) by means of the -ing suffix. These derived nominal gerunds, like their Old English ancestor, behave like regular nouns in all respects, taking adjectival modification and realizing participants periphrastically by means of an of-phrase. Semantically, indefinite nominal gerunds retain the event-like semantics of the base verb (the ing-suffix does not trigger a denotational shift but serves as "function-indicating coding", cf. Croft 1991: 58). Thus, indefinite nominal gerunds are distinct from so-called lexicalized ing-nominals with non-eventive or object-like denotation (e.g. Maekelberghe \& Heyvaert 2016, Fonteyn \& Hartmann 2016).

Interestingly, while there are a few studies on indefinite nominal gerunds in Present-day English (Maekelberghe \& Heyvaert 2016, see also Taylor (2000: 269) for a brief discussion), the construction has not been studied systematically from a historical or diachronic perspective. With the exception of some (brief) comments in the work by Tajima (1985) and De Smet (2008), there are virtually no studies devoted to the rise and development of indefinite nominal gerunds. Besides its being overshadowed by the rise of the verbalized gerund, there are two potential reasons why the emergence has been largely overlooked. First, there appears to be a strong trend in synchronic as well as diachronic literature to regard (nominal) gerunds as mass nouns (e.g. Brinton 1995, 1998), and indefinite articles occurring with nominal gerunds seem to be regarded as a rare phenomenon. In other words, given the dominant idea that indefinite nominal gerunds are extremely infrequent, they are most likely regarded as accidental individual coinages. Second, it is possible that, if anyone has noted the systematic increase of indefinite nominal gerunds in the Modern English period, they thought it to be part of a larger trend in English in which all abstract nouns start combining with indefinite articles more commonly. Yet, neither one of these assumptions have ever been tested, let alone systematically investigated using corpus data.

\section{Methodology, aims and outcomes}

The aim of this study is twofold. First, we aim to show that the indefinite nominal gerund can be considered a structural (and functional) novelty in the gerundive system, which is part of a larger process of diachronic nominalization. Second, we aim to come to a deeper understanding of why such innovations occur, i.e. whether the observed developments can be attributed to language processing factors or constraints that have previously been suggested as a cause of (or motivation for) linguistic change, more specifically those of isomorphism and system pressure. To attain these goals, we present a detailed qualitative and quantitative analysis of the Corpus of Late Modern 
English Texts (version 3.1; henceforth CLMET3.1; De Smet et al. 2015), which covers the period between 1710 and 1920 .

The analysis has been divided into largely two steps. First, we need to establish that the observed rise of the indefinite nominal gerund is not part of a substitution process, but rather a structural innovation in the gerundive system. To this end, we will show that the emergence of the indefinite nominal gerund did not occur simultaneously with the more general trend in English in which bare noun phrases are gradually replaced with those preceded by an indefinite article (Section 3.1). Subsequently, we strengthen this claim by providing a detailed referential-semantic analysis of bare and indefinite nominal gerunds (Section 3.2). An analysis of all bare nominal gerunds (e.g. an ill way of treating of men) and indefinite nominal gerunds (e.g. an ill treating of men) in CLMET3.1 shows that the referential profiles of the two constructions are too different to assume that the rise of the indefinite nominal gerund is really a replacement of its bare nominal predecessor.

Having established that the rise of indefinite nominal gerunds is a linguistic innovation, we can turn to the second part of the analysis, in which we investigate the cognitive mechanisms underlying the observed developments. In particular, we will address the role of isomorphism as a motivating factor in linguistic change and innovation. Isomorphism, as defined by Haiman (1980: 515) postulates "a one-to-one correspondence between the signans and the signatum, whether this be a single word or a grammatical construction" (often referred to as 'one-form-one-meaning', cf. Bloomfield (1933:145), Bolinger (1968:127), 'Humboldt's universal' in Venneman (1972); 'Avoid Synonymy Principle' in Kiparsky $(1983,2005)$ and Rainer (1988); 'Relational diagram: Difference of form' in Hiraga (1994: 13)). While isomorphism is often referred to as a synchronic principle, it has been argued to operate in language acquisition ('principle of contrast', which states language learners abide by the assumption that "wherever there is a different form in language, there is a difference in meaning" (Clark 1987)), and it has been claimed that, ultimately, language change is driven by some kind of force towards an isomorphic 'one-to-one' relation between form and meaning (cf. Anttila 1989: 407; see also Dressler et al.'s [1987] notion of biuniqueness or uniformity and Fertig's (2013: 106-109) section on 'one-function-one-form'), which means that "any word which a language permits to survive must make its semantic contribution" (Bolinger 1977: ix-xx).

In the last decades, a renewed interest in linguistic alternations and form-meaning relations in linguistic change has led to an overwhelming number of studies that depend on isomorphism as a language processing principle that explains the outcome of various types of morphological or even syntactic change. Drawing on the theory of 'natural mophology', Fertig (2013: 106ff.) explains that languages appear to have a "purported preference for a one-to-one correspondence between form and meaning/function in grammar" which is violated when multiple forms are used for the same meaning (i.e. synonymy), or when more than one formative is used to express a single function (i.e. 
multiple exponence, e.g. the past tense of sell - sold - is formed by both a vowel change and $-d)^{3}$. In morphologically motivated diachronic change, then, we expect to see that the language system indeed evolves in such a way that these violations are eliminated in order to restore a onefunction-one-form organization. Extending this idea to the realm of syntax, a multitude of variationist studies have indicated that different syntactic constructions also exhibit a functional-semantic division of labour, which involves (often very subtle) differences in meaning, perspective, or topicalization (e.g. Goldberg 1995, Gries \& Stefanowitsch 2004, Colleman 2009 for the dative alternation; Szmrecsanyi 2010 for the genitive alternation). Diachronically, if two forms exhibit a substantial amount of functional-semantic overlap, either one form is lost (i.e. substitution, see Croft 2000; e.g. De Smet 2008 for English gerunds; Nevalainen et al. 2011 for a range of Modern English examples) or each form develops in such a way that a functional-semantic division of labor between the two forms arises (see, among many others, Mondorf 2011; Nuyts \& Byloo 2015; Fonteyn \& van de Pol 2016), as to minimize isomorphic violations.

However, when it comes to explaining linguistic innovations like the rise of the indefinite nominal gerund, adopting isomorphism as an explanatory factor seems to be much less successful. It has been claimed that new forms are coined "freely and frequently, typically to fill [functional] gaps" (Clark 1987: 8). In the absence of such gaps, i.e. when another established form already exists to express a certain meaning, the institutionalization of a new form is said to typically be blocked or pre-empted by the existing form (whether it be a concrete token, like *stealer/thief, or a more schematic type, like zero-derivation for verbs on -ify, e.g. the verification/*verify of the document; see Aronoff 1976, Rainer 1988). Yet, in reality, it seems that (i) blocking is more than often violated (Plag 1999; Bauer, Lieber \& Plag 2013), as functional overlap between different forms is pervasive in languages at all stages (De Smet et al. forthc.). Moreover, recent diachronic studies have noted that (ii) functional-semantic overlap between different linguistic forms diachronically emerges over and over, and (iii) the principle of isomorphism does not account for cases where division of labor does not exist from the very start (De Smet et al. forthc.). Finally, it has been suggested that (iv) functional overlap might in fact be beneficial for a diachronically developing language: if it happens that functional gaps emerge, existing constructions in the language network that already play a role in the functional domain at issue will most likely serve as a linguistic safety net to avoid loss of function (Van de Velde 2014).

In the analysis presented below, it will be shown that at least three of the problems with the principle of isomorphism emerge when the rise of the indefinite nominal gerund is mapped out. In

\footnotetext{
${ }^{3}$ Fertig (2013) also lists homonymy and cumulative exponence (when a single form is used to mark multiple functions, e.g. Latin -orum which marks both plural and genitive) as violations of isomorphism. In the present study we will only consider violations involving multiple forms associated with a single meaning/function.
} 
the spirit of Meillet (1912), we consider a language as a system whose parts are interconnected. The notion of linguistic interconnections - like isomorphism - has been appreciated in cognitive (particularly constructional) approaches to language. Taylor (2004:49), for instance, argues that "each [linguistic] unit stands at the hub of a network of relations to other units". This 'network' - or so-called constructicon (e.g. Goldberg 2006: 64; Dabrowska \& Divjak 2015: 354) - is regarded as a schematic representation of the language in the mind of its users, and consists of a wealth of vertical relations between concrete instantiations of linguistic outings, and the more schematic, overarching abstract patterns they instantiate (e.g. Barðdal \& Gildea 2015: 23). In recent years, scholars have argued that the hierarchical constructional network of a language should be enriched with so-called horizontal links between constructions on the same level of abstraction ${ }^{4}$ (Van de Velde 2014, Norde 2014; Sommerer \& Smirnova 2017; Traugott forthc.). By including horizontal relations, it is suggested that the form-function relation of a particular construction is not only determined by the abstract schematic construction it instantiates, but "may be partly motivated in relation to its neighbours" (Van de Velde 2014: 147).

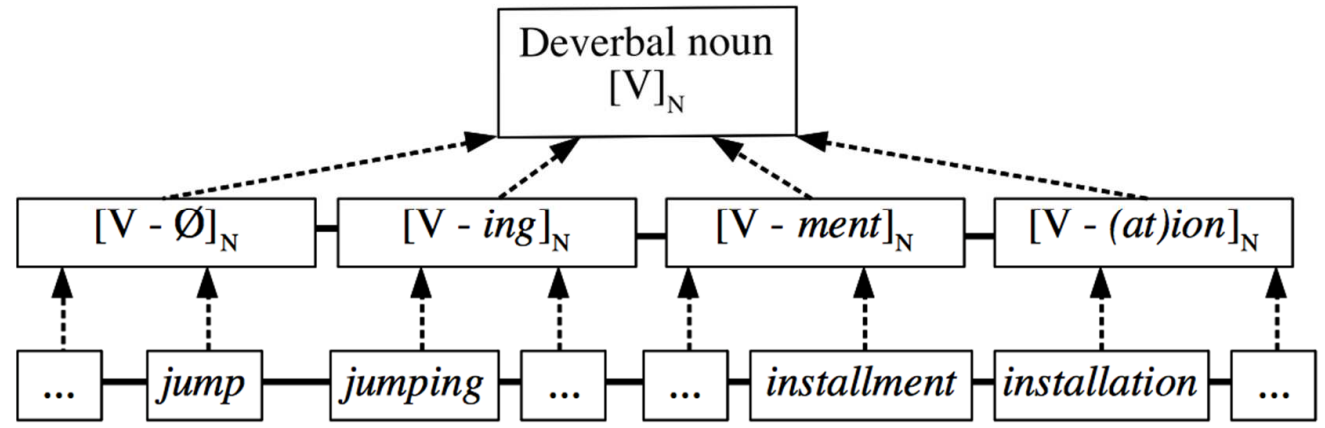

Figure 1 - Network of deverbal nouns in English. The dotted arrows represent instantiation relations: the bottom row represents all instantiations of the more schematic word formation patterns in the middle row, which in their turn instantiate the abstract category of 'deverbal noun'. The full, bold lines between the schematic patterns in the middle row, and the concrete instantiations on the bottom row represent the horizontal relations.

As illustrated in Figure 1, the functions associated with the nominal gerund (i.e. [V-ing $]_{\mathrm{N}}$ ), e.g. jumping, installing) are not only inherited from its overarching deverbal noun schema, but are also determined in relation to other nominalization strategies, like zero-derivation (i.e. [V- $\varnothing] \mathrm{N}$, e.g. jump), or the Latinate word formation patterns in -ion or -ment (e.g. installation, installment). It is these horizontal relations that are crucial to understanding the concept of isomorphism. In essence, isomorphism is a principle that heavily depends on a contrastive relation between constructions of the same level of abstraction. Because two instantiated forms (e.g. installment and installation) are

\footnotetext{
${ }^{4}$ Such horizontal links are also referred to as 'paradigmatic links', as they were inspired by the concept of morphological paradigms. The notion of paradigms is most commonly discussed in context of inflectional morphology, but is extended here to derivational morphology and syntactic constructions.
} 
different, isomorphism predicts that the language user will also recognize a difference in meaning between them, or, in other words, isomorphism exists on the horizontal axis, and defines those horizontal links as relations of contrast. In a strictly isomorphic system, then, any diachronically emerging new form fills a functional-semantic opening, which is contrastively related to the functional-semantic value of its neighboring forms.

For the case at present, this means that we can only determine whether the indefinite nominal gerund came to fill a functional gap if we compare its usage and development to that of its constructional neighbors, i.e. zero-derivations and Latinate word formations. Section 4 will present such an elaborate comparative analysis, based on data drawn from CLMET3.1. The analysis will show that, while indefinite nominal gerunds do seem to stay clear from the functional domain covered by Latinate suffixes (e.g. an installation, an arrangement), their emergence cannot be traced back to the existence of a functional gap. Instead, it appears that indefinite nominal gerunds occur in contexts where zero-derivations are already covering the intended functional-semantic value. As such, there is no clear functional division of labor between the indefinite nominal gerund and its neighboring constructions in the initial stages, which means there does not seem to be any blocking mechanism to pre-empt functional overlap that came with it, and the isomorphic principle is violated. In section 5 , finally, we will argue that, to explain the diachronic nominalization of nominal gerunds (and the functional overlap it creates), we cannot solely rely only on contrastive relations in the constructional network. Rather, to explain the observed developments, we need to regard them in light of system pressure and similarity-based forces.

\section{Analysis: innovation or substitution?}

\subsection{The indefinite nominal gerund: historical developments}

In Present-day English, nominal gerunds are commonly considered as abstract or, more generally, uncount nouns (Allen 1966; Mourelatos 1978; Brinton 1991, 1995, 1998; Maekelberghe \& Heyvaert 2016). In principle, then, nominal gerunds do not combine with the indefinite article or $-s$ pluralization (e.g. *a singing of a song / *two coughings) and show a variety of features associated with uncount nouns. A brief search in the Penn Parsed Corpus of Middle English (PPCME2) indicates that this is also the case in older stages of English, where we find that gerunds often take zerodetermination, as in (4), and indefinite quantification, as in (5):

(4) a. Spekyngge and styryngge of wycked companye ['Speaking and steering of wicked company'] hadde hard ywrout vppon me. (c1400, PPCME2)

(5) a. And if ze make ony departynge of your felaschype ['any departing of your fellowship'], pan haue a wetcheword be assent, be pe weche ze schall know whan ze 
mete with ony persone, wheper he be ony of zour watche or non. (1470-1500, PPCME2)

b. for eche membre of hooli chirche hap sum shewyng of pis spirizt ['some vision of this spirit'] (c1400, PPCME2)

Be that as it may, it was not entirely impossible for nominal gerunds to combine with an indefinite article, as illustrated in examples (6) and (7). As already pointed out by Tajima (1985: 66-71), the occurrence of nominal gerunds with determiners other than the definite article has received very little treatment. Between 1250 and 1500, Tajima finds 68 (out of 1383) nominal gerunds preceded by the indefinite article $a(n)$, which amounts to $4.9 \%$ of all nominal gerunds in his data set. A search of the Leuven English Old to New corpus (version 0.3; henceforth LEONO.3) shows that, between 1250 and 1500,30 (out of 1349 ) nominal gerunds were preceded by an indefinite article (2.2\%); so while the proportion of indefinite nominal gerunds seems to be somewhat lower than in Tajima's data set, both studies indicate that nominal gerunds preceded by indefinite articles were uncommon in Middle English.

(6) 3if a foule spot be in pi bodily visage, pe ize of pe same visage may not see pat spotte, ne wite wher it is, wib-outyn a myrour or a teching of anoper pan it-self: ri3t so it is goostly. (?a.1400, LEON0.3 > Helsinki Corpus)

'If a physical face has a stain, the eyes of that face cannot see that stain, nor know where it is without a mirror or a remark by another; just so it is with your spiritual face (i.e. the soul).' (De Smet 2008b: 65)

(7) All Hawkes generally are manned after one manner, that is to say, by watching and keeping them from sleep, by a continuall carrying of them vpon your fist, and by a most familiar stroaking and playing with them. (1615, PPCEME)

Strikingly, in the Late Modern English period, these indefinite nominal gerunds start playing an increasingly prominent role in the gerundive system. As pointed out by De Smet $(2008,2013)$, the overall frequency of nominal gerunds dropped in the Early Modern period, the main reason for this development being the gradual decline of the determinerless or bare nominal gerund. Still, despite this setback, the nominal gerundive construction retained its position in the language, and even started exhibiting structural innovation. As shown in Figure 2, the frequency of indefinite nominal gerunds steadily rose in the Late Modern period (1710-1920). 


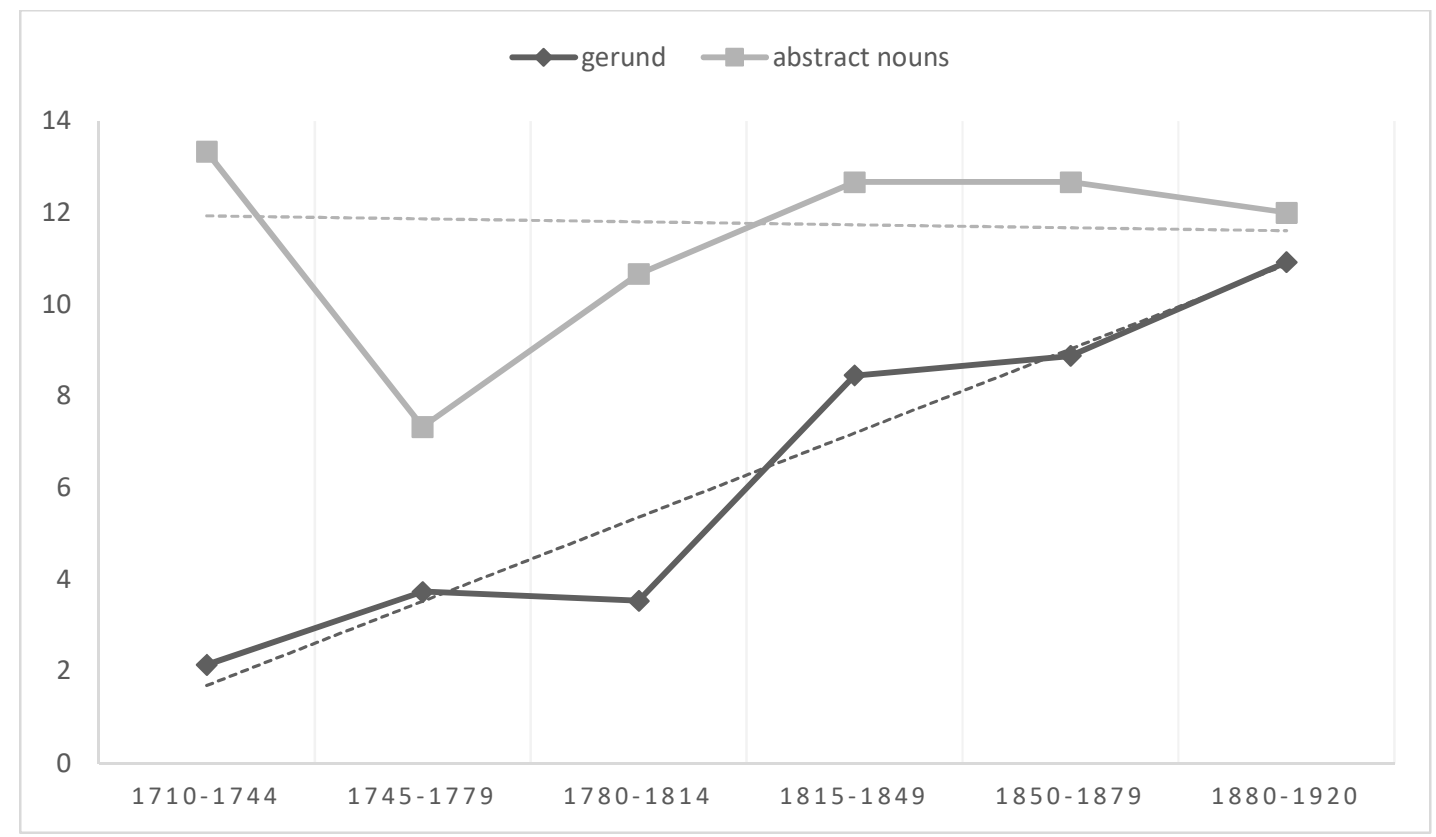

Figure 2 - Relative frequency (\%) of indefinite determiners occurring within the category of nominal gerunds vs. relative frequency (\%) of indefinite determiners occurring with other abstract nouns between 1710 and 1920 in CLMET3.1.

This rise of indefinite determiners with nominal gerunds is particularly interesting if one compares it to the use of indefinite articles with abstract nouns in general in the period under investigation (e.g. 'Tis seldom, however, that a love so ardent as mine, meets with a spirit so resigned in the same person. [CLMET3.1, 1748]). After extracting all the words tagged as nouns from CLMET3.1, we sampled out 150 randomly selected abstract nouns for each of the six subperiods shown in Figure 2 (1710-1744, 1745-1779, 1780-1814, 1815-1849, 1850-1879 and 1880-1920). By manually coding these abstract nouns, we found that between 1710 and 1920 about 20 out of 150 tokens (i.e. 13.33\%) take an indefinite article, which seems to decrease slightly towards the end of the Late Modern Period, when only 12 out of 150 abstract nouns occur with an indefinite article (12\%). The proportion of gerunds with indefinite articles, on the other hand, increases from 10 out of 466 tokens (2.15\%) to 262 out of 2,399 tokens (10.92\%). These trends (illustrated in Figure 2 ) can be compared by measuring the correlation between the increase of indefinite determiners with gerunds or other noun phrases and the passage of time (Gries \& Hilpert 2009), expressed by means of Kendall's $\tau$. If Kendall's $\tau$ has a positive value (between 1 and 0 ), it indicates that there is a positive trend (i.e. the proportion of indefinite articles increases over time), while a negative $\tau$ (between 0 and -1 ) indicates a negative correlation (i.e. the proportion of indefinite articles decreases over time). If $\tau$ approaches 0 , it indicates the absence of a (strong) trend, while values approaching either 1 or -1 indicate that there is a perfect correlation between the passage of time and the increase of indefinite 
articles. Comparing the trends, then, we find that the increase of indefinite articles with nominal gerunds has a $\tau$-value of $0.86(p=0.01)$ while the frequency change of indefinite articles with other abstract nouns has a $\tau$-value of -0.067 (indicating a slight decrease over time, which is not significant: $p=1) .^{5}$

\subsection{Additional evidence: referential-semantic analysis of bare and indefinite nominal gerunds}

In the previous section, we suggested that the rise of indefinite articles with nominal gerunds does not occur simultaneously with a more general upsurge of indefinite articles with abstract nouns. Still, this does not tell us whether the institutionalization of the indefinite nominal gerund should be regarded as a structural innovation, or whether the new form with indefinite article merely enters the language to take over functions of another formal predecessor.

Within the study of the diachronic development of the English gerund, a similar question has previously been asked by De Smet $(2008,2013)$. In an extensive corpus-based analysis, he teases out the functional motivations behind the well-studied rise of the verbalized gerund, stating that it can be explained as a diachronic process of substitution, as the verbal gerund gradually came to replace an older (and functionally less versatile) form. De Smet $(2008,2013: 136)$ starts his account of the rise of the verbal gerund by distinguishing three main types of gerund constructions, which serve as the locus of the major developments in Middle and Early Modern English: the definite nominal gerund (DNG), the bare nominal gerund (BNG), and the verbal gerund (VG) (as in (8a-c) respectively): ${ }^{6}$

(8) a. He defouleth the whole faith of his testimony, by the falsifying of one part (a1555,

Oxford English Dictionary; [De Smet 2013: 136])

b. That we fall not into disordering of ourselves by anger. (1559, Oxford English Dictionary; [De Smet 2013: 136])

c. I shall teach him a lesson, for filching hens or cocks (1552-1563, Helsinki Corpus;

[De Smet 2013: 136])

By highlighting the functional-semantic identity between bare nominal gerunds and verbal gerunds, De Smet is able to show that verbal gerunds automatically "calque the function and distribution of

\footnotetext{
${ }^{5}$ This rise of indefinite determiners with nominal gerunds also does not straightforwardly align with the more general increase of indefinite determiners with other NPs in (Late Modern) English. A corpus study of the CLMET3.1 using all words that were tagged as nominals indicates that between 1710 and 1920 the proportion of nominals combining with an indefinite article increases from 35,800 out of 410,914 tokens (i.e. noun phrases; $8.71 \%$ ) to 185,169 out of $1,806,333$ tokens $(10.25 \%)$. While the increase of indefinite articles with nominal gerunds had a $\tau$-value of $0.86(p=0.01)$, the increase of indefinite articles in general only has a $\tau$-value of 0.6 (which is not significant: $\mathrm{p}=0.13$ ).

${ }^{6}$ Note that De Smet $(2008,2013)$ does not include the indefinite nominal gerund as a separate category, as nominal gerunds preceded by an indefinite article are still extremely rare in Middle and Early Modern English.
} 
bare nominal gerunds" (De Smet 2013: 137; Fonteyn \& Heyvaert 2016), and "bare nominal and verbal gerunds compete with one another over the same set of environments" (De Smet 2008: 95). In particular, it seems that bare nominal gerunds that establish their referent through so-called "indirect clausal grounding" (for examples and explanation see Fonteyn [2016] and Langacker [2008]) were entirely replaced by verbal gerunds by the end of the Late Modern English period (Fonteyn, Heyvaert \& Maekelberghe 2015).

The remaining uses of bare nominal gerunds in Late Modern English, then, are either generic, as in example (12a), non-specific, as in example (12b), or specific indefinite, as in example (12c). Genericity typically involves reference to a class of entities (e.g. He loves dinosaurs), or, in the case of deverbal nominalizations, to a type of situation. (Non-)specific entities, on the other hand, refer to instances of a class. With non-specific reference, the instance referred to is arbitrary (e.g. He is looking for a car - "any car"), while the referents of specific indefinite entities are in some way linked to-and accessible through - the broader discourse context (e.g. He is looking at a car).

(12) a. Before mental training must come training of the body. (1891, CLMET3.1)

b. 'Don't! Can't you be fond of a cove without squeedging and throttling of him? (1846-1848, CLMET3.1)

c. Two lads disappear during the breakfast, go and dress themselves up, and then return, accompanied by music, dogs, children, and firing of pistols. (1852, CLMET3.1)

As such, the class of bare nominal gerunds now seems to largely overlap with the class of nominal gerunds preceded by an indefinite article, as indefinite nominal gerunds are also said to commonly express generic (13a), non-specific (13b), or specific indefinite (13c) reference (Fonteyn 2016; Maekelberghe \& Heyvaert 2016):

(13) a. What true art requires of us is a faithful rendering of a great experience. (1899, CLMET3.1)

b. Lady Caroline (...) uttered the last sentence, with its vague, far-reaching, and most damaging hint, without even a pricking of conscience. (1884, CLMET3.1)

c. (...) a noise, like that of a tumult, seemed to proceed from the prison below; it died away soon after, and a clanking of fetters was heard along the passage that led to my apartment. (1828, CLMET3.1)

Given that the frequency of bare nominal gerunds continues to decrease in this period - while the frequency of nominal gerunds with indefinite article starts its substantial rise (Figure 3) - it is tempting to assume that the rise of nominal gerunds with an indefinite article is related to the further demise of bare nominal gerunds. 


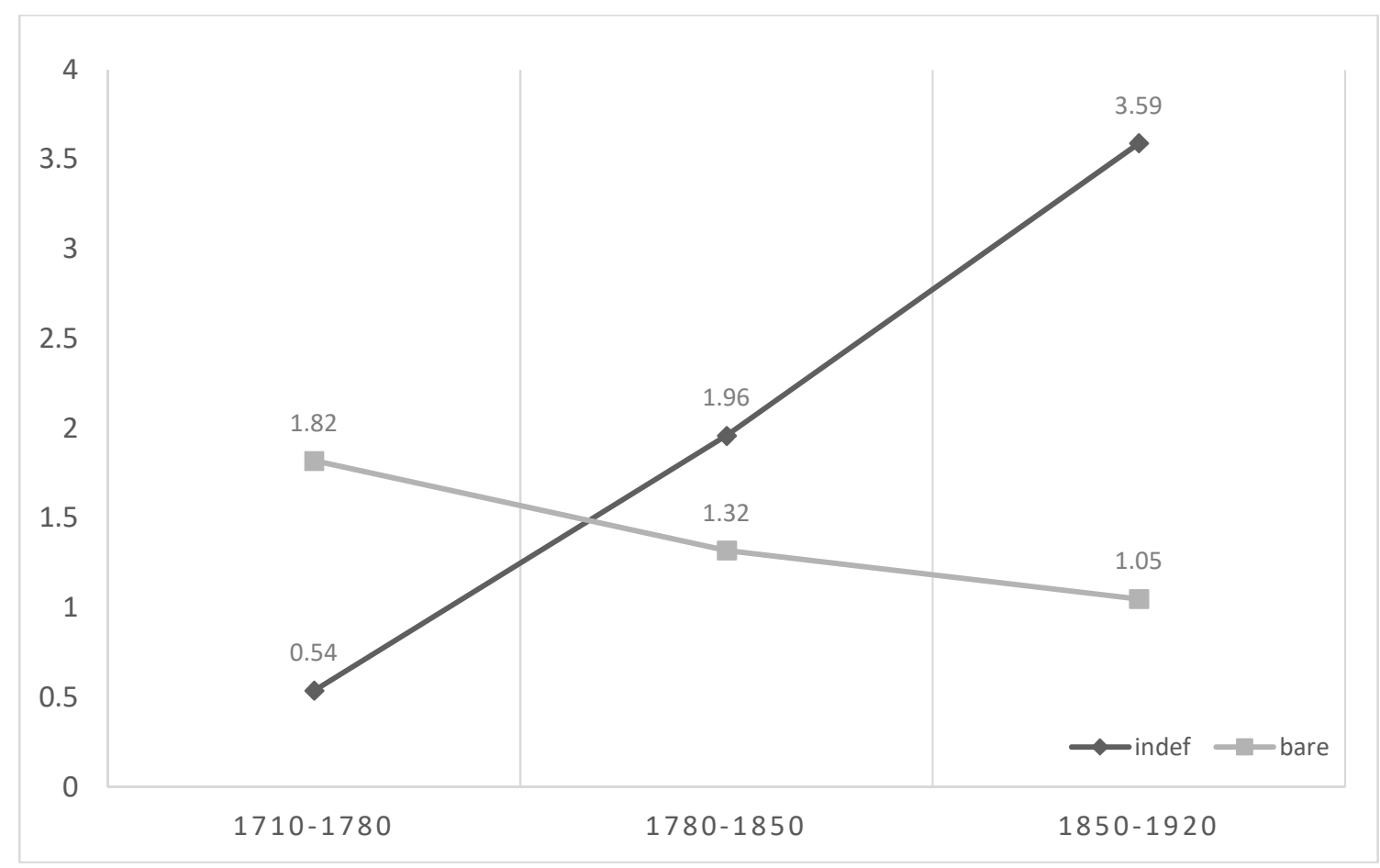

Figure 3 - Frequency of indefinite and bare nominal gerunds in Late Modern English (normalised frequency over 100,000 words)

In order to test this hypothesis, we conducted a referential analysis of all 732 indefinite nominal gerunds and 466 bare nominal gerunds occurring between 1710-1920 in CLMET3.1. If the indefinite nominal gerund replaced the bare nominal gerund, we would expect it to take over (parts) of the bare nominal gerund's referential profile, eventually ousting the latter in certain referential domains. In addition to the subtypes of generic, non-specific and specific indefinite reference, we also discerned a non-referential category, which involves attributive gerundive constructions that occur in the predicative complement slot of copular clauses, as in (14):

(14) a. My intention was to have stay'd here at least one day, to have looked into the Country had we met with fresh water convenient, or any other Refreshment; but as we did not, I thought it would be only spending of time, and loosing as much of a light Moon to little purpose (...) (1770, CLMET3.1)

b. These store casks were mounted on stands or horses (...) and then the butts and barrels were rolled to the door, without one ounce of lifting from the commencement of the process to the end. This was a great saving of labour. (1773-1835, CLMET3.1)

Before going into the results of the referential analysis, it is interesting to note that indefinite and bare nominal gerunds do not distinctively differ in the types of verbs they are derived from. This was revealed by means of a distinctive collexeme analysis (Gries \& Stefanowitsch 2004), which assesses the attraction of a certain lexeme to one member of an alternating construction (the indefinite 
nominal gerund) as opposed to the other (the bare nominal gerund). While a negligible number of verbs appear to be significantly attracted to the bare nominal gerund construction, amongst which making and giving, there are no verbs that significantly prefer the indefinite nominal gerund construction over the bare nominal gerund construction. Thus, the indefinite nominal gerund did not attract new verbs into the gerundive system, but rather drew on the verbs that were already available in the nominal gerund paradigm. This, one could argue, might be an argument in favor of the substitution hypothesis.

The referential analysis, however, paints a different picture. As can be observed in Figure 4 and Figure 5, neither bare nor indefinite nominal gerunds exhibit significant diachronic changes in their usage profile. Indefinite nominal gerunds already early on show a clear preference for specific reference, while bare nominal gerunds maintain the same proportions of referents with generic, specific and non-specific reference throughout the Late Modern English period. Importantly, then, the increase of indefinite nominal gerunds does not appear to affect the bare nominal gerund's usage profile in the same way as the verbal gerund did. As such, the rise of the indefinite nominal gerund appears to represent an innovation in the gerundive system rather than a substitution. This is clearly illustrated by the category of non-referential uses: up until the emergence of the indefinite nominal gerund, hardly any non-referential uses of nominal gerunds could be attested. As can be seen in Figure 4, however, non-referential uses represent the second-largest referential category with indefinite nominal gerunds. Crucially, it is the functional import of the indefinite article that facilitates the occurrence of nominal gerunds in these non-referential slots (cf. Depraetere \& Langford 2012: 95; see Maekelberghe \& Heyvaert 2016 for Present-day English gerunds). 


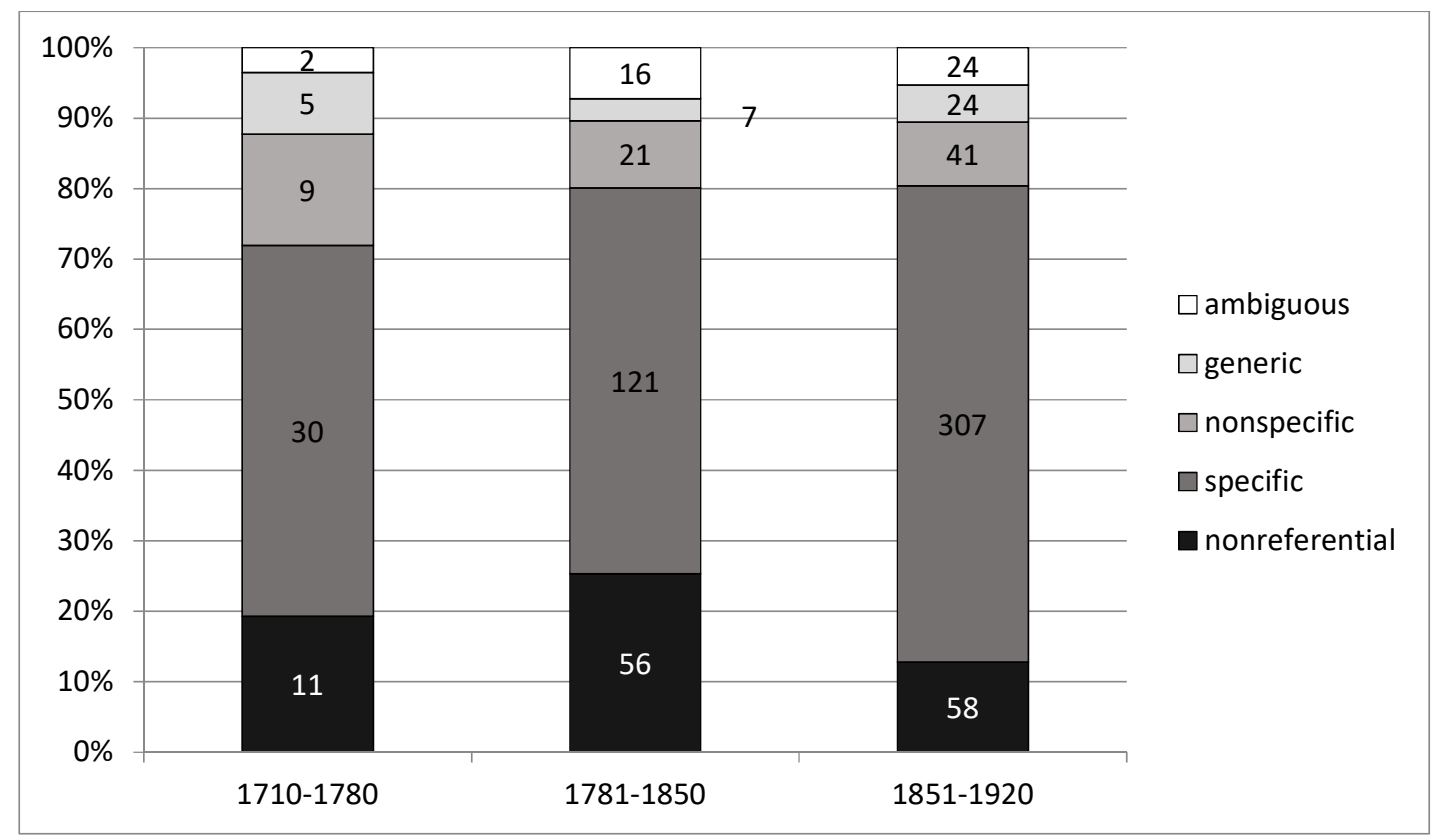

Figure 4-referential profile of nominal gerunds with an indefinite article

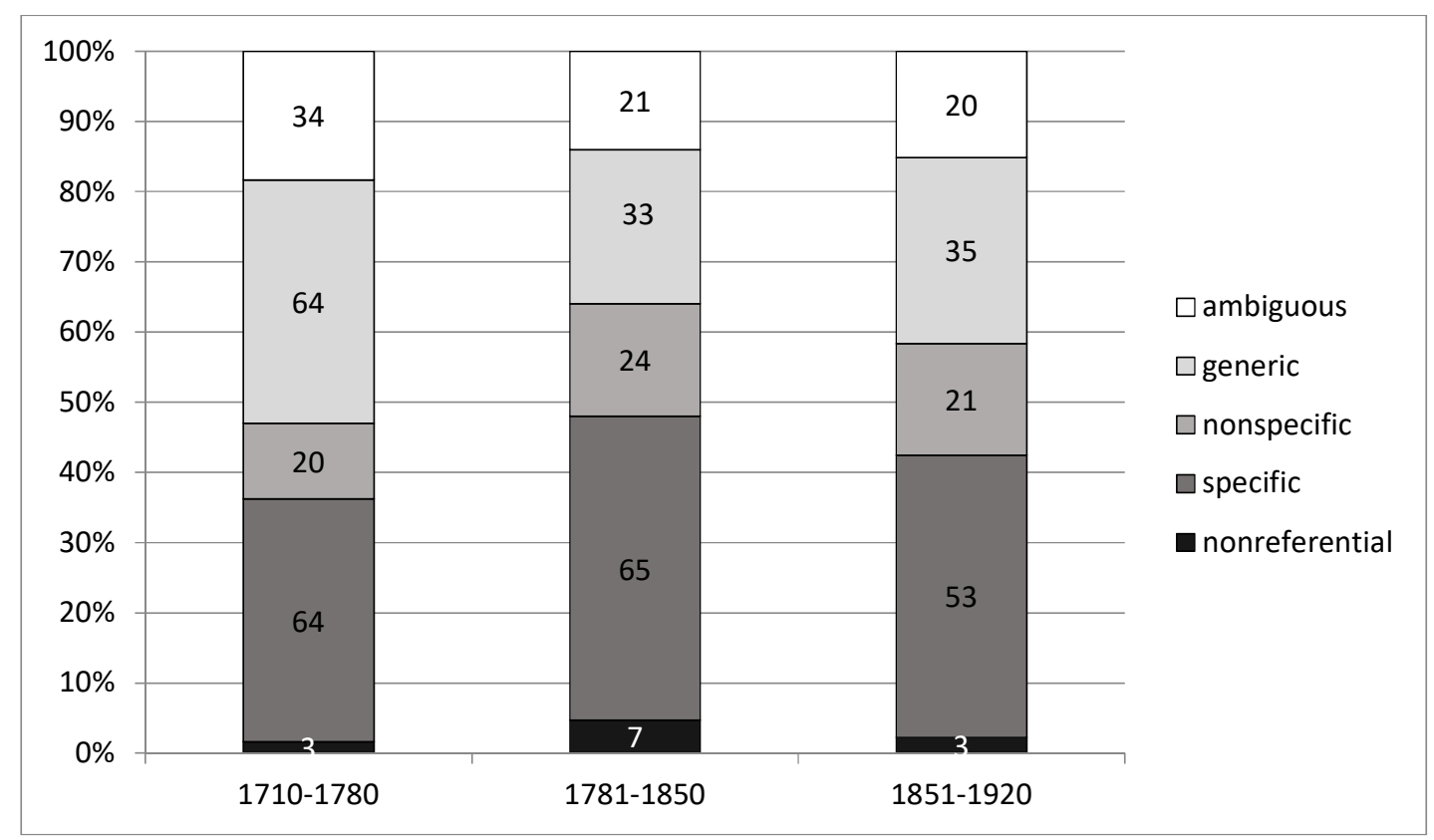

Figure 5 - referential profile of bare nominal gerunds

As far as system-internal competition is concerned, then, the indefinite nominal gerund does not appear to directly engage with the existing forms within the paradigm. Rather, the formal paradigmatic expansion represented by the indefinite nominal gerund is accompanied by functional innovation, introducing new referential options in the nominal gerund's usage profile. 
Thus, while most studies have mainly focused on the morphosyntactic verbalization of the verbal component of the English gerundive system, showing how a large subgroup of the English gerund gradually transformed from a nominal structure to a structure that exhibited an increasing number of features typically associated with a non-finite clause, it appears that the nominal component of the system to some extent also transformed. More specifically, the nominal gerund's increasing 'eagerness' to combine with the full range of structural features of the noun phrase can be considered a case of diachronic nominalization. We will come back to this in Section 5. First, we will have a closer look at what brought about this formal and functional innovation.

\section{The rise of indefinite nominal gerunds and its effects on the constructional network}

To further tease out possible motivations behind the diachronic nominalization of the nominal gerund, it is of course essential to consider the development against the background of their interaction with functionally equivalent forms. In Late Modern English - much like in Present-day English - the nominal gerund is only one of many forms that can be used to nominalize a verbal stem. The English 'nominalization network', then, comprises a range of different constructions with varying potential to occur with indefinite articles: nominal gerunds, which are generally believed to yield mass nouns (Brinton 1998: 48), derived abstract nouns in -(at)ion, -ment, -al, -age, -ance, -ure (Leech et al. 2009: 250), which are said to yield either mass or count nouns depending on the aspectual type of the base verb (Brinton 1998: 47), and so-called zero-derivations in which the verbal stem is used in a nominal slot without any overt function indicating morpheme (e.g. to kick $>$ a kick), generally yielding count nouns (Brinton 1998: 49).

Dividing the data from the CLMET3.1 into three periods, we find that in the first period (1710-1780) the 57 nominal gerunds with an indefinite article occur with 39 different verb types. For the second period (1780-1850), we find 163 different verb types among the 221 tokens. In the final period, then, the 454 nominal gerunds with indefinite article instantiated 264 different verb types.

\begin{tabular}{ccc}
\hline $\mathbf{1 7 1 0 - 1 7 8 0}$ & $\mathbf{1 7 8 0 - 1 8 5 0}$ & $\mathbf{1 8 5 0 - 1 9 2 0}$ \\
\hline 39 types & 163 types & 264 types \\
\hline
\end{tabular}

Table 1 - verb types occurring in indefinite nominal gerund construction per period

After extracting the verb stems from the different verb types per period, we used the part-of-speechtagged version of the CLMET3.1 corpus to collect all instances where the verbal stem occuring in the $a(n)+[\mathrm{V}-i n g]_{\mathrm{N}}$ construction (e.g. classif in a classifying of things, or twitch in a twitching of the lips) 
also occurred with one (or more) of the Latinate suffixes -(at)ion, -ment, -al, -age, -ance (e.g. a classification of things), or as 'zero' [V] $]_{\mathrm{N}}$-forms (e.g. a twitch of the lips). The results yielded by the search were manually checked for mistakes in the automated retrieval (e.g. adding irregular forms such as applause to the forms yielded for the stem applaud; removing irrelevant forms such as pursuance from the list of results for the verb stem purse) and part-of-speech-tagging (e.g. removing forms with non-nominal function which were mistakenly tagged as nominal). If the verbal stem occurred with different nominalization constructions in the manually corrected list, we considered them as potentially competing variants, which were taken into account for further analysis.

Before turning to the analysis of the alternating forms, we wish to point out that, in a substantial number of cases, the use of an indefinite nominal gerund seems to be motivated by the fact that the verb stem simply does not allow to be nominalized by means of any other strategy than the ing-suffix (or, at least, the verb stem does not occur as a zero-derived form or with a Latinate suffix). One example of this is the class of deadjectival verbs ending in -en, like lessen or sharpen, or verbs that are themselves derived from nouns by affixation, like unfold or overhaul (also see Bauer, Lieber \& Plag 2013: 203). Between 1710 and 1780, 13 out of 39 verb types solely nominalize with the ing-suffix (33.3\%). Between 1780 and 1850, 69 out of 163 types (42.3\%) belong to the nonalternating group, and, finally, between 1850 and 1920, 104 out of 264 types (39.4\%) do not allow alternation. A selection of examples from the non-alternating group from the three periods under investigation is provided in examples (15)-(17):

(15) a. This diminution, however, can scarce amount to any positive loss, but only to a lessening of the gain which it might otherwise make. (1766, CLMET3.1)

b. It is plain then, from such Instances as these, that it is possible, by an intermixing of Species, that there are Creatures in the World whose Form and Intellects are so join'd, that no body can pretend to determine justly whether they are Men or Brutes. (1751, CLMET3.1)

(16) a. A shadow even on that shadowed face, a sharpening even of the sharpened features, and a thickening of the veil before the eyes into a pall that shuts out the dim world, is come. (1844, CLMET3.1)

b. This is no part of the Christian religion, but a preparatory awakening of the soul: a means of dispersing those gross films which render the eye of the spirit incapable of any religion, much less of such a faith as that of the love of Christ. (1847, CLMET3.1)

c. Peter quoted these verses, especially the last, with a truculent frown, and a brandishing of the musket. (1832, CLMET3.1)

d. A sudden overhauling of his pockets produced some stray halfpence. (1841, CLMET3.1)

(17) a. It is highly probable, too, that just now there was a heightening of the divine expression on that unworldly face, derived from an intensification of the inner life. (1914, CLMET3.1) 
b. She felt a tightening of the fingers that clasped hers. (1894, CLMET3.1)

c. And now let us go on to consider how, by a further unfolding of this same fundamental notion, there is a gradual formation of the first germs of science. (1861, CLMET3.1)

d. Has not science, too, its embryology? And must not the neglect of its embryology lead to a misunderstanding of the principles of its evolution and of its existing organisation? (1861, CLMET3.1)

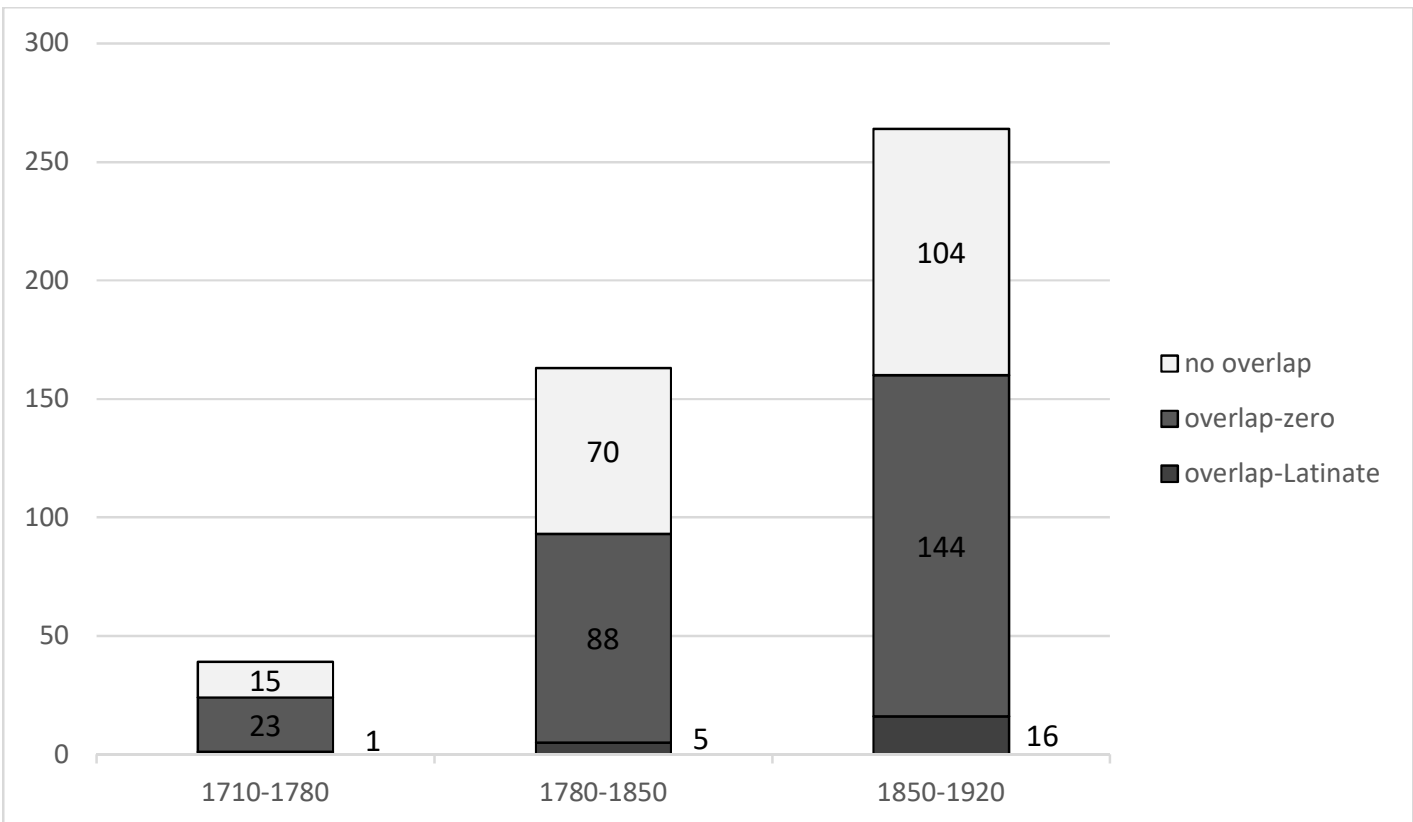

Figure 6 - Functional overlap of indefinite nominal gerunds with neighbouring constructions (Latinate nominalizations and zero-derivations) expressed in absolute type frequency

Within the group of types allowing alternation, we considered the competition between indefinite nominal gerunds and Latinate nominalizations separately from the competition between indefinite nominal gerunds and zero-derived nominalizations.

\subsection{Latinate suffixes}

With regard to the competition between indefinite nominal gerunds and derived nominals in a Latinate suffix, we find that functional overlap is sparse. In the first period under investigation (17101780), there are 39 different verb types that occur in the indefinite nominal gerund construction, of which only 1 type also occurs with a Latinate suffix (2.6\%):

(18) a. For as sleep naturally draws the animal heat inwards, and the heat of the sun counteracts this power, by drawing it outwards; sleeping in the day is a resisting of nature, which must be prejudicial to the health of the body. 
b. Here Ernest 's unconscious self took the matter up and made a resistance to which his conscious self was unequal, by tumbling him off his chair in a fit of fainting. (1903, CLMET3.1)

c. M. Armagnac specialized rather in a resistance to militarism, and wished the chorus of the Marseillaise altered from "Aux armes, citoyens" to "Aux greves, citoyens". But his antimilitarism was of a peculiar and Gallic sort. (1914, CLMET3.1)

Between 1780 and 1850, only 5 out of 163 verb types also occur as a derived nominal with a Latinate suffix (3.1\%).

(19) a. (...) and a long way down; looking curiously at the bridges, signals, lamps, and wondering when another Devil would come by. A trembling of the ground, and quick vibration in his ears; a distant shriek; a dull light advancing, quickly changed to two red eyes, and a fierce fire, dropping glowing coals; (1844, CLMET3.1)

b. (...) the rope broke, as French ropes often did; or else an Amazon cut it. Abbe Lefevre falls, some twenty feet, rattling among the leads; and lives long years after, though always with 'a tremblement in the limbs.' (1837, CLMET3.1)

(20) a. I now told the justice that I was no Irishman, nor had ever been in that country: I was a native of England. This occasioned a consulting of the deposition in which my person was supposed to be described (...) (1794, CLMET3.1)

b. All her faith in her recovery is now built upon going abroad; she is earnest to set off immediately; but Dr Lyster has advised her to make London in her way, and have a consultation of physicians before she departs. (1782, CLMET3.1)

(21) a. Literature, so far as it is Literature, is an "apocalypse of Nature", a revealing of the "open secret." (1840, CLMET3.1)

b. I know Marianne 's heart: I know that she dearly loves me, and that I shall not be the last to whom the affair is made known, when circumstances make the revealment of it eligible. (1811, CLMET3.1)

(22) a. These hills are amongst the most barren of the downs of England; yet a part of them was broken up during the rage for improvements; during the rage for what empty men think was an augmenting of the capital of the country. (1882, CLMET3.1) b. An augmentation of capital, much more rapid than that of population, must soon reach its extreme limit, unless accompanied by increased efficiency of labor (through inventions and discoveries, or improved mental and physical education) (1848, CLMET3.1)

Finally, between 1850 and 1920, we see a slight increase of derived nominal alternatives, with 16 out of 264 verb types also occurring with a Latinate suffix (6\%). 
(23) a. All night long the tempest grew fiercer, and I think no one in Moonfleet went to bed; for there was such a breaking of tiles and glass, such a banging of doon and rattling of shutters, that no sleep was possible. (1898, CLMET3.1)

b. The fresh breakage of a branch, the barking of a tree-stem, the lately nibbled grass, with the sap still oozing from the delicate blade, the disturbed surface of a pool; everything is noted, even to the alarmed chatter of a bird: nothing is passed unheeded by an experienced hunter. (1855, CLMET3.1)

(24) a. Painting is only possible as a quasi-hieroglyphic epitomising of nature (1912, CLMET3.1)

b. They can not remember even a single development, much less can they remember that infinite series of developments the recollection and epitomisation of which is a sine qua non for the unconsciousness which we note in normal development. (1912, CLMET3.1)

(25) a. The development of intelligence is, under one of its chief aspects, a classifying of the unlike things previously confounded together -- a formation of sub-classes and sub-sub-classes, until the once confused aggregate of objects known, is resolved into an aggregate which unites great heterogeneity among its multiplied groups, with complete homogeneity among the members of each group. (1862, CLMET3.1)

b. If human thought proceeded with the orderly method which abstract logic would suggest to it, we might go further and say that a classification of natural entities should be the first step in science itself. (1920, CLMET3.1)

(26) a. They chirp to each other, the scattered birds reunite; there is a fluttering and twittering, a rearranging of mates, then again songs, feeding, love, jealousy, and bickerings. (1874, CLMET3.1)

b. The principal cause of this common phenomenon is what is known as "metamorphism" - that is, the subjection of the rock to a sufficient amount of heat to cause a rearrangement of its particles. (1877, CLMET3.1)

Note that not all Latinate alternatives are in a true alternation relation with the indefinite nominal gerund, i.e. the co-existence of the two forms is motivated by a distinction in meaning. In the case of nourish, illustrated in example (27), the indefinite nominal gerund is used to refer to the act of nourishing, while the Latinate nominalization nourishment refers to food, or more abstractly, to substances needed for growth or health. The nominalization nourishment overall behaves as an uncount noun, and it never occurs with an indefinite article in our data set. Similarly, while settling in 
(28a) refers to the act of settling or arranging something, the Latinate nominalization settlement most often refers to a location $(28 b):^{7}$

(27) a. Mr. Craig, who was present, and who never lost an opportunity of testifying, as he said, his "discountenance of the crying iniquity," remonstrated with Mr. Daff on the unchristian nature of the proposal, stigmatising it with good emphasis "as a sinful nourishing of carnality in his day and generation." (1821, CLMET3.1)

b. And the lads who drive plough, which must certainly be a healthy exercise, are very rarely seen with any appearance of calves to their legs: a circumstance which can only be attributed to a want either of proper or of sufficient nourishment.

(28) a. In course I didn't intrewde myself when they was a settling of the himportant bizziness as they was cum about, so I strolled off to a little willage as I seed in the distance (1890, CLMET3.1)

b. We were to travel together, with our ulterior destination a settlement in Canada West (1856)

b. Besides, there were reports of a settlement of fierce runaway negroes on the Serra de Mururaru, and it was considered unsafe to go far in that direction (1863)

It could also be noted that there is a relation between (productivity of) affixes and text type and style (Baayen \& Renouf 1996: 90): in the case of Latinate suffixes such as -(at)ion, it has been suggested that they are recognized as non-native derivational suffixes and as such have certain stylistic associations (Cowie 1998), which potentially do not affect the native ing-suffix. In our data set there do not seem to be any striking differences in the extent to which nominal gerunds compete with Latinate nominalizations between different text types. ${ }^{8}$

\subsection{Zero-derivation}

The overlap between nominal gerunds with an indefinite article and zero-derivations, on the other hand, seems more substantial, despite the fact that it has been claimed on a few occasions that zero-

\footnotetext{
${ }^{7}$ It should be pointed out that this does not mean that only Latinate nominalizations can refer to object(-like) concepts. In fact, ing-nominals already exhibited object(-like) semantics in Middle English (Dalton-Puffer 1996: 93ff.). Gradually, Latinate nominalizations also became associated with object-semantics as more lexemes were borrowed into Middle English (Dalton-Puffer: 123). Both ing-nominals and Latinate nominalizations can be used to refer to object(-like) concepts in Early and Late Modern English (cf. Fonteyn forthc.) and Present-day English (Bauer, Lieber \& Plag 2013), and there even appears to be a growing tendency for ing-nominals to refer to non-action semantics (Fonteyn \& Hartmann 2016). Such non-action ing-nominals (e.g. a building, a painting) quite commonly occurred with the idefinite article even before Late Modern English.

${ }^{8}$ CLMET3.1 includes text from 6 genres: Narrative Fiction, Narrative non-fiction, Drama, Letters, Treatises, and 'Other'. Nominal gerunds and Latinate nominalizations occur in all text types, and overlap between the strategies is limited in all genres. However, studies like for instance Cowie (1998) show that stylistic motivations for using -(at)ion productively are mainly associated with scientific and medical texts. As such, although the matter falls outside the scope of this study, it would still be interesting to pursue a more detailed diachronic stylistic analysis of competition between nominalization strategies.
} 
nominalizations are semantically different from overtly affixed nominalizations (i.e. that they are not "overt analogues"; Sanders 1998). Plag (2003), for instance, argues that there are at least two remarkable systematic differences between the two forms (based on Cetnarowska 1993: 113). The first difference is that the zero-form of transitive verbs will have a specialized meaning while ingforms of the same transitive verb have a more general meaning. The second difference is that, if a base verb can be used both transitively and intransitively, the ing-nominalization will be related to the transitive usage of the verb, while the conversion will be related to the intransitive usage (e.g. we say the beating of the prisoners but the beat of my heart; Plag 2003: 113). However, at least between 1710 and 1920, these claims do not hold. In example (30), for instance, intransitive tap has the same general meaning regardless of the adopted nominalization pattern, and in (29) both nominalized forms of spread/change result in transitive events (with the of-phrase of the zero-form also expressing the verb's direct object rather than its subject):

(29) b. he had now been instrumental in turning the attention of many, and to witness a considerable spreading of the cause. (1836, CLMET3.1)

a. The ill effects arising from intoxication, are a changing of the natural tone of the stomach. (1735-1820, CLMET3.1)

b. (...) through a change of habit or circumstance, an organism is permanently subject to some new influence (...) (1867, CLMET3.1)

(30) a. (...) and Mrs. O'Dowd, with a tap of her whip, told the Major to be quiet. (18471848, CLMET3.1)

b. For the sound was more like a light tapping of a little hammer than an actual step. (1910, CLMET3.1)

To ensure maximum comparability between indefinite nominal gerunds and zero-forms, then, we extracted all zero forms followed by an of-phrase, and subsequently supplemented the more superficial lemma comparison to a careful manual analysis aimed at setting out a detailed comparison between the meaning of the word formation products of the indefinite nominal gerund construction (e.g. a clashing) and their zero-equivalents (e.g. a clash).

Between 1710 and 1780, 31 out of 39 types seem to occur both as nominal gerunds as well as zero-derivations. On closer inspection, 8 types were disregarded, as the zero form did not occur as an eventive nominalization but was without any exception used to express non-eventive meanings (e.g. fish, whip, jar). As such, 23 out of 39 types (58.9\%) are nominalized by means of the indefinite nominal gerund as well as the zero-form. Between 1780 and 1850, 117 types also occurred in the zero-form, with 29 unequivocally expressing non-eventive meanings (e.g. word, shadow, flag, fire). Disregarding the non-eventive zero-forms, then, we find that 88 out of 163 types $(53.9 \%)$ simultaneously occur as indefinite NGs as well as zero-nominalizations. Between 1850 and 1920, 
finally, we found 190 verb types that occurred as indefinite nominal gerunds as well as zero-forms. Seeing that 46 of those had unambiguous non-eventive semantics in all their occurrences (e.g. heat, bottle, train, cloud, wound), we are left with overlap in 144 out of 264 types (55\%).

The considerable amount of overlap in base verbs allowing both zero-derivation and indefinite nominal gerunds does not come as a surprise, as both word-formation processes readily combine with all different kinds of verb classes (Brinton 1998). On various occasions, it has been claimed that the alternation is in fact semantically motivated (Quirk et al. 1985: 1551; Mourelatos 1978; Brinton 1991, 1995, 1998). For Present-day English, it appears to be more or less generally accepted that (indefinite) nominal gerunds and zero-forms crucially differ with respect to the aspectual value attributed to the word formation process: the ing-suffix, it has been claimed, "has the effect of converting a situation into an activity, of making the situation durative, atelic, and dynamic" (Brinton 1998: 48), turning punctual verbs like tap into durative activities (e.g. there was a continual tapping of these heavy drops upon the dead leaves [1874, CLMET3.1]). As such, its meaning is seen as largely separate from that of zero-derivations, the latter being considered as "unitexcerpting" nominalizations, whereby "a single instance of this specified equivalent unit [i.e. tap] is taken" (Talmy 1988: 176-7; also see Brinton 1998: 51; emphasis added). To assess these claims for the Late Modern English data, we conducted a more detailed functional-semantic analysis of the overlapping forms, focusing in particular on their aspectual features.

If we further scrutinize the area of overlap between indefinite nominal gerunds and zeroderivations in Late Modern English by analyzing the aspectual properties of the nominalization patterns, we find that the variation can be functionally justified, albeit only partially. After selecting all verb types that occurred both as indefinite nominal gerunds and zero-derivations, we manually coded all instances for viewpoint aspect, which is concerned with "how the speaker wants to represent the internal temporal structure of a situation" (Declerck 2006: 28) rather than the inherent temporal meaning of the situation. For this study, we only focused on the iterativeness of the event. Iterativity is defined as the successive occurrence of identical subsituations on one particular occasion (in contrast to repetitiveness, which involves the occurrence of a situation on multiple occasions; Declerck 2005: 35-36). In our data set, we distinguished between single (31a-b), iterative $(32 a-b)$ and ambiguous situations, for which both a single and iterative reading is possible, as in (33ab). ${ }^{9}$

\footnotetext{
${ }^{9}$ In addition to viewpoint aspect, we also manually coded the data for lexical aspect, and argument type. We distinguished states (ai), activities (aii), accomplishments (aiii), achievements (aiv) and semelfactives (av), which are categorized based on four basic ontological features, viz. dynamicity, durativity, telicity and transitionality (Smith 1997, Declerck 2006).

(a) i. [-dynamic, +durative, -telic]: I know it is only a Desire of Youth (1766, CLMET3.1) ii. [+dynamic, +durative, -telic]: I must refresh myself with a reading of Clarendon (1828, CLMET3.1)
} 
a. Then with a catching of her breath, she murmured: "Mr. Eager and Charlotte, dreadful frozen Charlotte". (1908, CLMET3.1)

b. "All aboard!" is the signal for taking places, but on this occasion a loud shout of "Tumble in for your lives!" greeted my amused ears. (1856, CLMET3.1)

(32) a. A lively scrimmage followed, amid a general cracking of ribs and snapping of spines. (1890, CLMET3.1)

b. (...) nothing remained of the pretty fall which had fed it but a miserable trickle of drops from the cascade above. (1905, CLMET3.1)

(33) a. During the progress of this dialogue there was a nervous twitching of Boldwood's tightly closed lips. (1874, CLMET3.1) [single twitch or multiple twitches]

b. Alick's brow darkened for a moment, and there was a formal exchange of greetings as the guest retreated. (1865, CLMET3.1) [one exchange between guests or multiple exchanges between different guests]

In each period, there seems to be a (weak) correlation between form and singular event meaning (1710-1780: $\varphi=0.314 ; 1780-1850: \varphi=0.384 ; 1850-1920: \varphi=0.276)$. Zero-derivations express singular events in the vast majority of cases (93.6\%) between 1710 and 1780 , but the relative frequency of singular events expressed by zero-forms decreases to $78.9 \%$ between $1850-1920$ ( $p<$ $0.0001 ; \varphi=0.189)$. In the group of indefinite nominal gerunds, we find a more even distribution of aspectual types. Indefinite nominal gerunds are often iterative or ambiguous between a singular and iterative reading, but (perhaps somewhat surprisingly) they express singular event in most cases $(55.6 \%$ to 41.9$) .{ }^{10}$

iii. [+dynamic, +durative, +telic]: It causes a fall of price that runs through society (1917, CLMET3.1)

iv. [+dynamic, -durative, +transitional]: with a catching of her breath, she murmured (1908, CLMET3.1)

v. [+dynamic, -durative, -transitional]: I heard a loud clap of thunder (1797, CLMET3.1)

The arguments in the of-phrase were also coded as single (e.g. a flashing of a distant light), plural (a beating of distant lights) or mass forms (a flashing of light). In each period, neither lexical aspect nor argument type yielded any significant differences between indefinite nominal gerunds and zero-derivations.

${ }^{10}$ The semantic overlap between indefinite nominal gerunds and zero-derivations is even more striking when we make a separate comparison for semelfactives, which is commonly regarded as the aspectual subcategory that most clearly demonstrates the proposed singularity vs. iterativity division of labour between nominal gerunds and zero-forms in Present-day English (e.g. Brinton 1998). Given the extremely marginal occurrence of zero-forms expressing iterative events, the dominant semantic profile of zero-derivations seems to be single event meaning. However, while zero-derivations express single events significantly more often than indefinite nominal gerunds in both periods $(p<0.0001)$, the data show that an increasing share of indefinite nominal gerunds will be used to refer to a single event, and the strength of the correlation between form and single event meaning decreases (1710-1780: $\varphi=0.737$; 1780-1850: $\varphi=0.606 ; 1850-1920: \varphi=0.402$ ). 


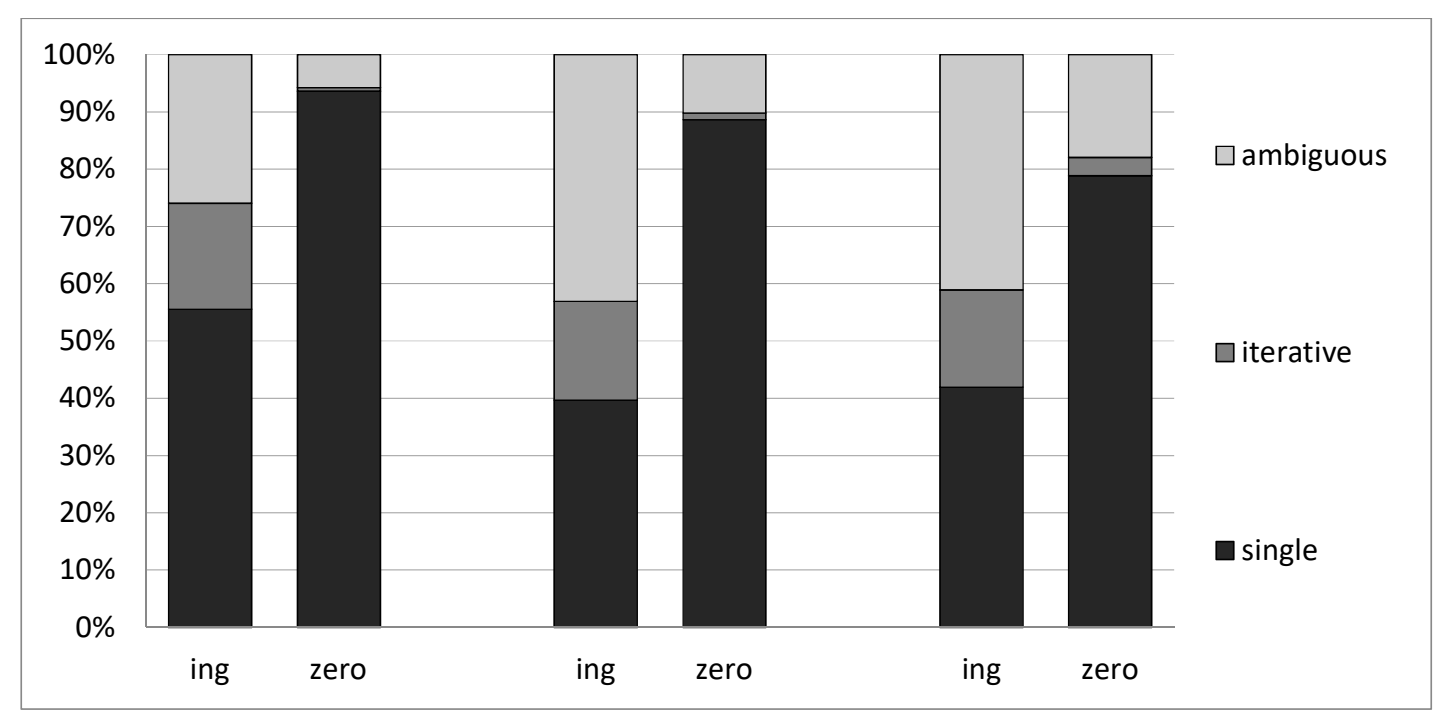

Figure 7-relative frequency (\%) of single, iterative, and ambiguous readings for indefinite nominal gerunds and zeroderivations per period.

\subsection{Discussion}

In a final synthesizing analysis, we considered the entire set of indefinite nominal gerunds, and determined the relative frequency of the functional-semantic overlap that emerged with the rise of indefinite nominal gerunds (cf. Figure 8).

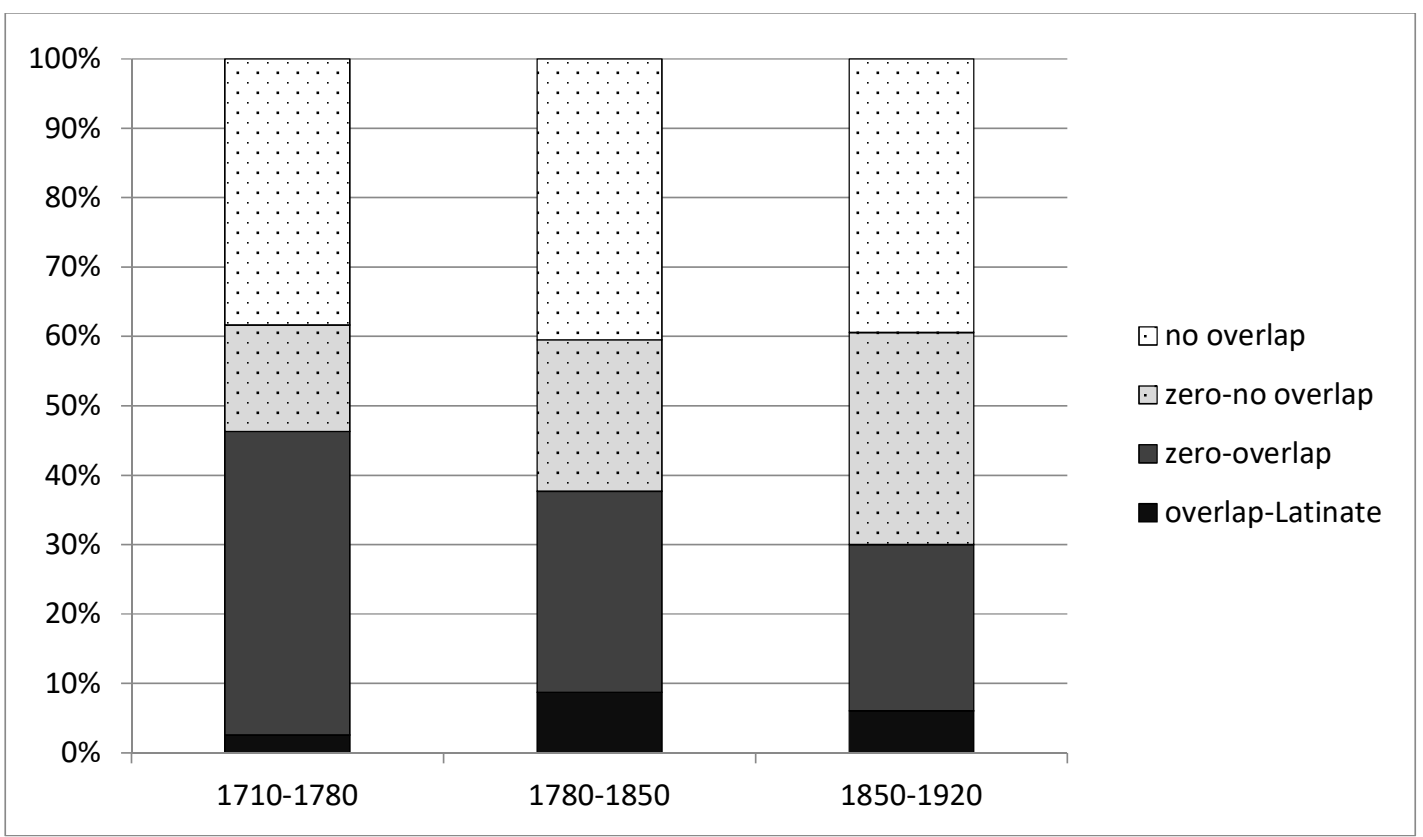

Figure 8 - relative frequency (\%) of functional overlap between indefinite nominal gerunds and its neighboring constructions (i.e. Latinate nominalizations and zero-derivations). 
There are two important observations to be made here. First, 38.4 to 40.5 percent of indefinite nominal gerunds are formed with verbs that do not combine with Latinate suffixes or do not occur as zero-forms. An additional 15.4 to 30.6 percent does occur in the zero-form, but the choice for the indefinite nominal gerund construction appears to be semantically motivated in these contexts, as the zero-form expresses a single event whereas the nominal gerund evokes an iterative reading. In those cases, we can assume that generally one (and only one) form is assigned to one meaning. Overall, the figures also indicate that, as indefinite nominal gerunds grow more frequent, the functional overlap between indefinite nominal gerunds and other nominalization strategies decreases, and the construction (very tentatively) moves towards its own functional niche (significant, weak effect: $p=0.03, \varphi=0.169$ ). Given that non-overlapping uses of indefinite nominal gerunds represent the majority of its uses in each period under investigation, it is tempting to use these observations as support for the idea that the rise of indefinite nominal gerunds is a case of functional gap-filling: the nominal gerund, which was originally an abstract noun, started allowing indefinite determiners in those contexts where other nominalization strategies failed to combine with a given base verb, or where the word-formation product of the other strategies had a different (specialized) meaning. Considering the rise of indefinite nominal gerunds as motivated by the existence of a functional niche would also be in support of the blocking theory, as the combination of nominal gerunds with indefinite articles is less successful in those contexts where there are functional competitors readily available.

However, we are confronted with the fact that there is still a considerable amount of functional overlap. Between 1710 and 1780, 46.4 percent of indefinite nominal gerunds can be considered to functionally overlap with Latinate or zero-alternatives. In these cases, we do find that isomorphism is violated, as multiple forms can be used for the same function ${ }^{11}$. What is interesting about these figures is that they indicate that the motivations for the emergence and rise of the indefinite nominal gerund are substantially different from those explaining its subsequent spread and development. More specifically, while the widely attested drive towards isomorphism can account for the attested decrease in functional overlap between indefinite nominal gerunds and their competitors, it does not explain why the usage profile of indefinite nominal gerunds (initially) exhibits such a large amount of functional overlap with zero-derivations. Moreover, the general applicability and strength of isomorphic principles seems quite problematic in light of the fact that

\footnotetext{
${ }^{11}$ In the case of the competition between nominal gerunds and zero-derivation, it could even be argued that the nominal gerund (unlike zero-derivation) additionally violates the isomorphic principle, in that it exhibits multiple exponence (cf. Fertig 2013: 106): both the -ing suffix and the distributional combination with the indefinite article mark the nominalized status of the base verb.
} 
the very emergence of these nominalizations was not prevented or blocked in the first place. ${ }^{12}$ Any explanations for the emergence of indefinite nominal gerunds (and the functional overlap it brings about), then, need to be sought elsewhere ${ }^{13}$.

\section{System pressure as a motivation for emergence}

In order to understand the systematic rise of indefinite nominal gerunds, we need to consider this structural innovation as part of a larger, more abstract development affecting the English nominal gerund. As pointed out in section 2, the fact that nominal gerunds more systematically start combining with indefinite articles brings the nominal gerund a step closer to exhibiting the full range of structural features of the noun phrase. As such, the change can be considered part of the

\footnotetext{
${ }^{12}$ Given the high type and token frequency of indefinite nominal gerunds (and the relatively low number of hapax legomena), it seems like the phenomenon constitutes more than a set of 'accidental' coinages, which would be licensed by blocking (cf. Bauer 1983). Before Late Modern English, indefinite nominal gerunds occur only sporadically, and it is still plausible that the attestations of indefinite nominal gerunds in the LEON corpus (and Tajima's attestations in the Helsinki corpus) are traces of individual productivity. However, the overall usage of indefinite nominal gerunds (and its rise in frequency described in Section 3) in Late Modern English is more suggestive of the fact that the pattern is institutionalized and productive on the population level (cf.
} Bauer 2003).

${ }^{13}$ One reviewer suggested that it would be interesting to consider the hypothesis that zero-derivations (and Latinate nominalizations) "are strong competitors in case they are (...) lexicalized, i.e. are stored in the mental lexicon, while nominal gerunds are (...) produced on-line". This would be in line with Kiparsky's (1983) suggestion that productive word formations are not (always) blocked by a (more) lexicalized alternative. However, it should be pointed out here that, in general, neither of these nominalization patterns are suffering from stagnated productivity in Modern English: Dalton-Puffer (1996) and Bauer, Lieber \& Plag (2013) both underscore the continued productivity of nominal gerunds as well as conversion up to the present-day (and see Cowie (1998) and Bauer, Lieber \& Plag (2013) on the continued productivity of -(at)ion). As such, it does not naturally appear to be so that indefinite zero-derivations and indefinite nominal gerunds can co-exist because zero-derivations have become part of the 'lexicon', while the other was governed by the 'on-line' creative linguistic device (similar to what Chomsky (1970: 215) suggests when he argues that "the transformational hypothesis is correct for gerundive nominalization and the lexicalist hypothesis for derived nominals and perhaps, though much less clearly so, for the mixed forms"). Furthermore, even if it is the case that only a subset of all event-referring zero-derivations (e.g. kick, hit, etc.) are stored in the lexicon, it is extremely difficult to prove that this is the case for historical languages (for which there are no native speakers left alive to subject to psycholinguistic study). In fact, even for present-day language, "a clear-cut distinction between what is and what is not institutionalized can be hard to establish" (Bauer, Lieber \& Plag 2013). A final point we would like to mention is that, if we would explain the observed overlap between zero-derivation and nominal gerunds by drawing on the idea that the lexicon is and entirely separate system from grammar, we might be relying too much on what has been termed 'the rule-list fallacy' (Langacker 1987). In other words, such an explanation would assume that complex words are either generated by rule or stored in the lexicon, while psycho-linguistic research has indicated that the outputs of rule-governed word formation products can in fact still be stored as well (e.g. Baayen et al. 1997). Based on what we know about the nominalization strategies under investigation here, we tentatively want to suggest that both zero-derivation and -ing affixation are situated on an intermediate level of a syntax-lexicon continuum (cf. e.g. Goldberg 1995), rather than constituting a set of stored versus rule-governed words. In section 5, we wish to offer an explanation as for why nominal gerunds start to become associated with a new grammatical property, which increases their functional overlap with zero-derivation without relying on the supposed separation of lexicon and grammar. 
diachronic nominalization of the nominal gerund, as it gradually acquires the full range of properties of the nominal category to which it belongs (Malchukov 2004, 2006). ${ }^{14,15}$

It is important to note that such changes do not take place in a vacuum. Diachronic nominalization defined as the gradual tendency for linguistic items to adjust to central members of the class inherently takes into account that linguistic change is affected by contemporaneous structures that are functionally similar to the one undergoing change. In fact, the development can be subsumed under the structuralist notion of "system pressure", which refers to the tendency for languages to form coherent systems that treat forms like similar forms (Blevins \& Blevins 2009; Haspelmath 2014). Crucially, system pressure can serve as a motivating factor of change, and has on occasion been put forward as a force of linguistic change that eliminates violations of one-form-onemeaning by reducing the number of forms that can be employed to express a particular meaning (Fertig 2013). However, system pressure could also account for the syntactic innovation affecting the nominal gerund, which eventually leads to new violations of one-form-one-meaning. As pointed out by McMahon (1994), the structuralist notion of the 'coherent system' strongly depends on symmetry and a disfavor for so-called paradigmatic 'gaps'. The power of symmetry as a motivating factor in linguistic change has mainly been developed to explain sound shifts (McMahon 1994: 29) or change in inflectional systems (cf. Wurzel's [1987, 1989] notion of 'system congruity', i.e. the 'naturalness/optimality' of a paradigm is determined by its internal consistency, which can potentially conflict with the principle of uniformity or isomorphism), but it has recently also been argued that the rise (and change) of syntactic constructions can also be explained through such paradigmatic gaps (Itkonen 2005; Fischer 2008; Hoffmann 2017). In a diachronic study on comparative correlative constructions, Hoffmann states that:

“... adopting a usage-based constructionist approach allows us to reinterpret this Structuralist notion of gaps as gaps in the mental constructional network. (...) The missing $\mathrm{C} 1 \mathrm{C} 2$ the-the comparative correlative construction constituted a gap in the [Old English] constructional

\footnotetext{
14 The definition provided here is a diachronic interpretation of the definition provided by Malchukov (2004, 2006) for the synchronic transcategorial process of nominalization. As argued by Malchukov (2004: Chapter 12), nominalization (and verbalization) are most commonly defined as synchronic operations, but the synchronic definitions often also allow for a diachronic interpretation. Note that the definition provided here is a simplified one that only touches on the recategorizing aspect of transcategorial shift. In reality, "transcategorial operations such as nominalization involve both decategorization and recategorization" (Malchukov 2006) as the shift involves both a loss of properties from the linguistic item's original category (i.e. decategorization, cf. Hopper and Thompson 1984), as well as the acquisition of properties belonging to the new category (i.e. recategorization, cf. Bhat 1994).

15 Diachronic nominalization, like grammaticalization, is a cross-linguistically attested process, in which nonprototypical members of the nominal class become more prototypically nominal on a structural as well as a functional-semantic level (for more examples see Malchukov 2004: Ch. 12; Demske 2002; Fonteyn, De Smet \& Heyvaert 2015; Fonteyn \& Hartmann 2016).
} 
network that was identified via analogy, and, consequently, filled via analogization." (Hoffmann 2017: 365-366) ${ }^{16}$

The case in the present study indeed seems to be quite similar in that the lack of systematic (or institutionalized) occurrence of indefinite articles with nominal gerunds constitutes a gap in the nominal paradigm. Considering the use of articles with English nouns, we find that there are essentially three major categories: the definite article, the indefinite article, and a zero-article (resulting in a bare noun phrase). A noun like stone, for instance, is rendered a mass noun that designates a substance or material when used as a bare noun phrase, as in (45a). This mass noun reading also occurs when the noun combines with a definite article, as in (45b). In some cases, however, stone combines with a definite article or, crucially, an indefinite article, to refer to a unit of this substance, as in (34c) and (34d) respectively:

(34) a. Three miles from this village a large town was seen, in the front of which, towards the sea, was an angular kind of fortification, built of stone, and near five feet high.

(1773-1774, CLMET3.1)

b. They saw some of the finest meadows that were ever beheld, and met with a few rocky places, the stone of which is sandy, and seemed to be admirably adapted for building. (1773-1774, CLMET3.1)

c. (...) but he found his pains fruitless, his arguments unavailing, and his endeavours, like the stone of Sisyphus, rolling back upon himself. (1753, CLMET3.1)

d. (...) the Chief who had been declaiming, after uttering a sentence, took up a stone and threw it against the side of the ship. (1773-1774, CLMET3.1)

In example (34c) and (34d), the conceptualization of stone differs from that in (34a) and (34b) in that the noun phrases "have a bounded shape, which we typically associate with objects" (Radden \& Dirven 2007: 71). Similarly, abstract nouns like knowledge generally exhibit the same range of options, occurring either as bare noun phrases, as in (35a), or taking a definite or indefinite article, as in (35b) and (35c) respectively:

\footnotetext{
${ }^{16}$ The concept of analogization here is used synonymously to the diachronic interpretation of system pressure. However, analogy and system pressure are not synonymous. As explained by Haspelmath (2014), analogy is often treated as operating on the token level, spreading from concrete token to token (regardless of the higher order category to which it belongs). Yet, higher-level and lower-level analogy are tightly linked, and token levelanalogy can lead to syntactic change (Fischer 2008). With a type-token ratio of 30/43 (and 17 hapax legomena), it seems unlikely the diachronic nominalization of the nominal gerund was initiated by one (or a few) exemplars in the present case. We tentatively assume, then, that the paradigmatic gap was analogically determined for the category in its entirety.
} 
a. Knowledge by theory only is such a vague, uncertain light. (1748, CLMET3.1)

b. Possessed by a superstition which worships the symbols of knowledge instead of the knowledge itself, they do not see that only when his acquaintance with the objects and processes of the household (...) a child be introduced to the new sources of information which books supply. (1861, CLMET3.1)

c. (...) not, it may be, a rational knowledge; but still a knowledge (...) (1861, CLMET3.1)

The use of the indefinite article with abstract nouns is said to occur when the abstract concept is bounded or delineated in some way (Quirk et al. 1985: 287; Declerck 1991: 338; Swan 2005: 132; Allen 1960: 195), that is by being "attributed to a [specific] person", or "premodified and/or postmodified" (Quirk et al. 1985: 287), as for instance by the adjective rational in (35c). In sum, then, English nouns seem to have the following paradigmatic options:

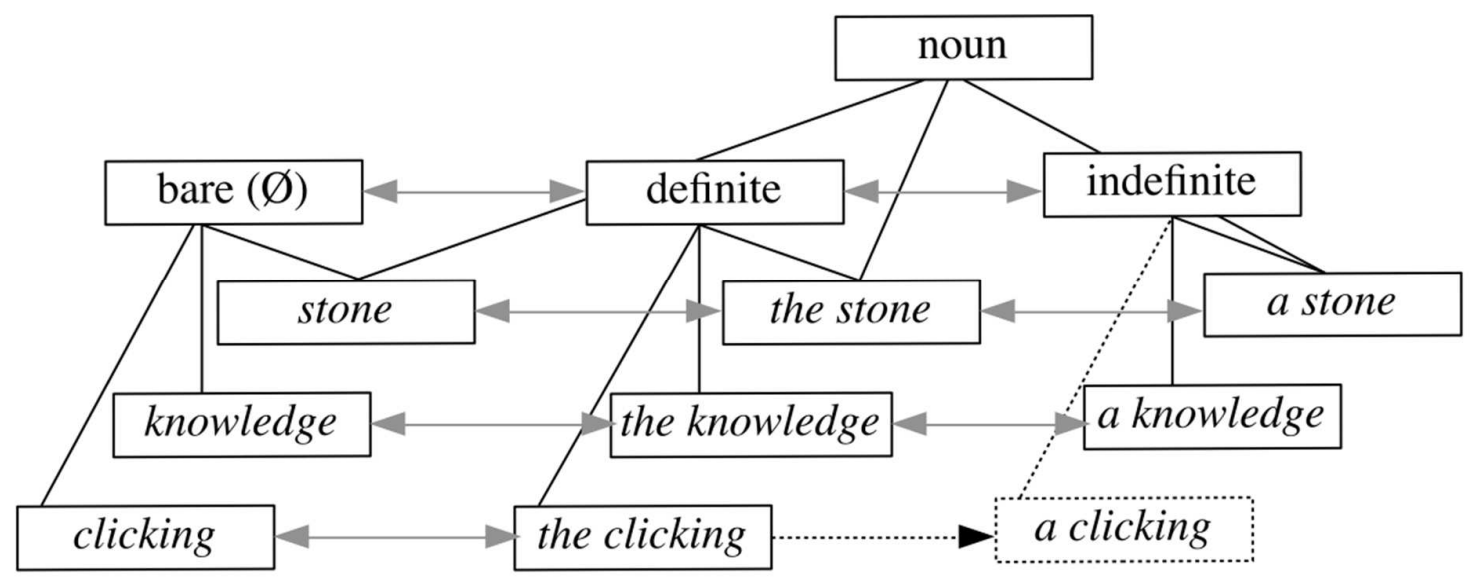

Figure 9 -Schematic representation of paradigmatic symmetry in the English nominal system. The dotted arrow represents the emergence of indefinite articles combining with nominal gerunds, thus adding a missing paradigmatic option for nominal gerunds and increasing its similarity to other members of the nominal category.

As indicated in Section 2, nominal gerunds quite commonly occurred as bare noun phrases, or with a definite article before 1710. Between 1710 and 1780, it appears that there is a lack of an institutionalized use of indefinite determiners with nominal gerunds (as compared to other abstract nouns), as indefinite nominal gerunds seem to be more or less incidental coinages, as they only sporadically occur (10 out of 466 tokens, $2.15 \%$ ). After 1780 , then, the presence of abstract nouns with indefinite articles - combined with an increased association of nominal gerunds with the nominal paradigm (cf. Fonteyn 2016) - potentially enables the language user to recognize analogical ties between them. As a consequence, they are also enabled to start using indefinite articles with nominal gerunds to express delineated or "particularized" events more systematically (Heyvaert \& Maekelberghe 2016). 


\section{Conclusion}

In this paper, we presented an in-depth corpus-based study of the rise and institutionalization of the indefinite nominal gerund in Late Modern English, considering the observed developments in light of their interactions with neighboring constructions in the language network. We argued that the rise of indefinite nominal gerunds constitutes an instance of diachronic nominalization, in which the nominal gerund over time gradually comes to exhibit the full range of properties associated with the nominal class to which it belongs. The analysis further indicated that, while a considerable share of indefinite nominal gerunds occupy their own functional niche, this (tentative) division of labor only gradually emerges. In other words, what we observe is not a linguistic innovation that is pre-empted where unneeded, but a more general rise of indefinite nominal gerunds that eventually flourish in those environments where competition with other forms is low or non-existent. Thus, while these figures do support the frequently investigated claim that language systems have a preference for a one-form-one-meaning organization, they also challenge the idea that functional overlap between different constructions is strongly avoided at all times (strong interpretations of isomorphism), and that new constructions are blocked in contexts where an alternative is readily available.

As such, the observed developments are particularly interesting and relevant in light of more general issues regarding the role of isomorphism in language change, and the importance of acknowledging the existence of competing motivations in synchronic usage and diachronic change. In particular, it raises the question why, if functional overlap between different surface forms is dispreferred, it arises in the first place. In this study, we argued that structural innovations in the language network need not necessarily arise through the existence of a functional gap that is not covered by existing forms, but can be influenced by system pressure. This view is in line with more recent studies in which similarity-based forces like system pressure are considered not just a mechanism, but also a cause or enabling factor of linguistic change and innovation (Hoffmann forthc.; De Smet et al. forthc.; Fischer 2008; Itkonen 2005). Crucially, then, the picture presented in the present study adds evidence to the idea that the long-term development of linguistic constructions (such as the diachronic nominalization of the English nominal gerund) can be the result of competing - even maximally opposite - forces, with system pressure temporarily overruling other cognitive motivations such as the desire for isomorphic one-to-one form-meaning relations. 


\section{References}

Allen, Robert L. 1966. The verb system of Present-Day American English. The Hague: Mouton de Gruyter.

Baayen, Rolf Harald \& Antoinette Renouf. 1996. Chronicling the times: Productive lexical innovations in an English newspaper. Language 72. 69-96.

Baayen, Rolf Harald, Dijkstra, Ton \& Robert Schreuder. 1997. Singulars and plurals in Dutch: Evidence for a parallel dual-route model. Journal of Memory and Language 37(1). 94-117.

Anttila, Raimo. 1989. Historical and comparative linguistics. Second edition. Amsterdam: John Benjamins.

Aronoff, Mark. 1976. Word formation in Generative Grammar. Cambridge, Mass.: MIT Press.

Barđdal, Johanna \& Spike Gildea. 2015. Diachronic Construction Grammar: Epistemological context, basic assumptions and historical implications. In Johanna Barðdal, Elena Smirnova, Lotte Sommerer \& Spike Gildea (eds). Diachronic Construction Grammar, 1-50. Amsterdam: John Benjamins.

Bauer, Laurie. 1983. English Word-formation. Cambridge: Cambridge University Press.

Bauer, Laurie. 2003. Introducing Linguistic Morphology. Edinburgh: Edinburgh University Press.

Bauer, Laurie, Lieber, Rochelle \& Ingo Plag. 2013. The Oxford reference guide to English morphology. Oxford: Oxford University Press.

Blevins, James P. \& Juliette Blevins. 2009. Analogy in grammar: Form and acquisition. Oxford: Oxford University Press.

Bloomfield, Leonard. 1933. Language. New York: Holt.

Bolinger, Dwight. 1968. Aspects of language. New York: Harcourt, Brace, and World.

Bolinger, Dwight. 1977. Meaning and form. London : Longman.

Booij, Geert. 2010. Construction Morphology. Oxford: OUP.

Brinton, Laurel J. 1988. The development of aspectual systems: aspectualizers and post-verbal particles. Cambridge: Cambridge University Press.

Brinton, Laurel J. 1991. The mass/count distinction and aktionsart: the grammar of iteratives and habituals. Belgian Journal of Linguistics 6. 47-69.

Brinton, Laurel J. 1995. The Aktionsart of deverbal nouns in English. In (Pier Marco Bertinetto ed), Temporal Reference, Aspect and Actionality. Vol. 1: Semantic and Syntactic Perspectives, 2742. Torino: Rosenberg \& Sellier.

Brinton, Laurel J. 1998. Aspectuality and countability: a cross-categorial analogy. English Language and Linguistics 2(1). 37-63. 
Cetnarowska, Bozena. 1993. The Syntax, Semantics and Derivation of Bare Nominalisations in English. Katowice: Uniwersytet Śląski.

Chomsky, Noam. 1970. Remarks on nominalization. In Roderick A. Jacobs \& Peter S. Rosenbaum (eds.), Readings in English Transformational Grammar, 184-221. Waltham: Ginn.

Clark, Eve V. 1987. The principle of contrast: A constraint on language acquisition. In Brian MacWhinney (ed.), Mechanisms of language acquisition, 1-33. New Jersey: Lawrence Erlbaum Associates.

Colleman, Timothy. 2009. Verb disposition in argument structure alternations: A corpus study of the Dutch dative alternation. Language Sciences 31. 593-611.

Comrie, Bernard. 1976. The syntax of action nominal. A cross-language study. Lingua 40. 177-201.

Comrie, Bernard \& Sandra A. Thompson. 1985. Lexical nominalizations. In Timothy Shopen (ed.), Language typology and syntactic description, Vol. 3, 349-398. Cambridge: Cambridge University Press.

Cowie, Claire. 1998. Diachronic word-formation: A corpus-based study of derived nominalizations in the history of English. PhD dissertation, University of Cambridge

Croft, William. 1991. Syntactic categories and grammatical relations: The cognitive organization of information. Chicago, IL: University of Chicago Press.

Croft, William. 2000. Explaining language change: An evolutionary approach. Second edition (revised). Oxford: Oxford University Press.

Croft, William. 2001. Radical Construction Grammar: Syntactic theory in typological perspective. Oxford: Oxford University Press.

Dabrowska, Eva \& Dagmar Divjak. 2015. Handbook of Cognitive Linguistics. Berlin: De Gruyter.

Dalton-Puffer, Christiane. 1996. The French influence on English morphology. A corpus-Based study of derivation. Berlin: Mouton De Gruyter.

De Smet, Hendrik. 2008. Functional motivations in the development of nominal and verbal gerunds in Middle and Early Modern English. English Language and Linguistics 12(1). 55-102.

De Smet, Hendrik. 2013. Spreading patterns: Diffusional change in the English system of complementation. Oxford: Oxford University Press.

De Smet, Hendrik \& Liesbet Heyvaert. 2011. The meaning of present participles. English Language and Linguistics 15. 473-498.

De Smet, Hendrik, D'Hoedt, Frauke, Fonteyn, Lauren \& Kristel Van Goethem. forthc.. The changing functions of competing forms. Cognitive Linguistics. Accepted with minor revisions.

Declerck, Renaat. 1989. Boundedness and the structure of situations. Leuvense Bijdragen 78. 275308.

Declerck, Renaat. 1991. A comprehensive descriptive grammar of English. Tokyo: Kaitakusha. 
Declerck, Renaat. 2005. Spatial and temporal boundedness in English motion events. Journal of Pragmatics 37(6). 889-917.

Declerck, Renaat. 2006. The grammar of the English tense system: A comprehensive analysis. Berlin: Mouton de Gruyter.

Demske, Ulrike. 2000. Zur Geschichte der ung-Nominalisierung im Deutschen. Ein Wandel morphologischer Produktivität. Beiträge zur Geschichte der deutschen Sprache und Literatur 122. 365-411.

Demske, Ulrike. 2002. Nominalization and argument structure in Early New High German. ZAS Papers in Linguistics 27. 67-90.

Depraetere, Ilse. 1995. On the necessity of distinguishing between (un)boundedness and (a)telicity. Linguistics and Philosophy 18(1). 1-19.

Depraetere, Ilse \& Langford, Chad. 2012. Advanced English grammar: A linguistic approach. London: Continuum.

Donner, Morton. 1986. The gerund in Middle English. English Studies 67. 394-400.

Dressler, Wolfgang U., Wolfgang U. Wurzel, Willi Mayerthaler\& Osvald Panagl (eds.). 1987. Leitmotifs in Natural Morphology. Studies in language companion series, 10. Amsterdam: John Benjamins.

Einenkel, Eugen. 1914. Die Entwicklung des englischen Gerundiums. Anglia 38. 1-76.

Emonds, Joseph E. 1973. The derived nominals, gerunds, and participles in Chaucer's English. In Braj B. Kachru \& Robert B. Lees (eds.), Issues in linguistics: Papers in honor of Henry and Renée Kahane, 185-189. Urbana: University of Illinois Press.

Fanego, Teresa. 1996. The development of gerunds as objects of subject-control verbs in English (1400-1760). Diachronica 13. 29-62.

Fanego, Teresa. 2004. On reanalysis and actualization in syntactic change: The rise and development of English verbal gerunds. Diachronica 21. 5-55.

Fertig, David. 2013. Analogy and morphological change. Edinburgh: Edinburgh University Press.

Fischer, Olga. 1992. Syntactic change and borrowing: the case of the accusative-and-infinitive construction in English. In Marinel Gerritsen \& Dieter Stein (eds.), Internal and external factors in syntactic change, 17-89. Berlin: Mouton de Gruyter.

Fischer, Olga. 2008. On analogy as the motivation for grammaticalization. Studies in Language, 32(2). 336-382.

Fonteyn, Lauren, De Smet, Hendrik \& Liesbet Heyvaert. 2015. What it means to verbalize: The changing discourse functions of the English gerund. Journal of English Linguistics 43(1). 36-60.

Fonteyn, Lauren, Heyvaert, Liesbet \& Charlotte Maekelberghe. 2015. How do gerunds conceptualize events? A diachronic study. Cognitive Linguistics 26(4). 583-612. 
Fonteyn, Lauren. 2016. From nominal to verbal gerunds: A referential typology. Functions of Language 23(1). 82-106.

Fonteyn, Lauren \& Stefan Hartmann 2016. Usage-based perspectives on diachronic morphology: A mixed-methods approach towards English ing-nominals. Linguistics Vanguard 2(1).

Fonteyn, Lauren \& Nikki van de Pol. 2016. Divide and conquer: The formation and functional dynamics of the Modern English -ing-clause network. English Language and Linguistics 20(2). 185-219.

Givón, Talmy. 1985. Iconicity, isomorphism, and non-arbitrary coding in syntax. In John Haiman (ed.), Iconicity in syntax, 187-220. Amsterdam: John Benjamins.

Goldberg, Adele E. 1995. Constructions: a Construction Grammar Approach to Argument Structure. Chicago: University of Chicago Press.

Goldberg, Adele E. 2006. Constructions at work: The nature of generalization in language. Oxford: Oxford University Press.

Gries, Stefan Th. \& Anatol Stefanowitsch. 2004. Extending collostructional analysis: A corpus-based perspective on 'alternations'. International Journal of Corpus Linguistics 9(1). 97-129.

Haiman, John. 1980. The iconicity of grammar: Isomorphism and motivation. Language 56. 515-540.

Haspelmath, Martin. 2014. On system pressure competing with economic motivation. In Brian MacWhinney, Andrej L. Malchukov \& Edith A. Moravcsik (eds.), Competing motivations in grammar and usage, 197-208. Oxford: Oxford University Press.

Heyvaert, Liesbet. 2003. A cognitive-functional approach to deverbal nominalization in English. Berlin: Mouton De Gruyter.

Heyvaert, Liesbet. 2004. Towards a symbolic typology of -ing nominalizations. In Michel Achard \& Suzanne Kemmer (eds.), Language, culture and mind, 493-506. Stanford: CSLI.

Hilpert, Martin \& Stefan Th. Gries. 2009. Assessing frequency changes in multi-stage diachronic corpora: Applications for historical corpus linguistics and the study of language acquisition. Literary and Linguistic Computing 24(4). 385-401.

Hiraga, Masako K. 1994. Diagrams and metaphors: Iconic aspects in language. Journal of Pragmatics 22. 5-21.

Hoffmann, Thomas. 2017. Construction Grammar as cognitive structuralism: The interaction of constructional networks and processing in the diachronic evolution of English comparative correlatives. English Language and Linguistics 21(2). 349-373.

Hopper, Paul J. \& Sandra A. Thompson. 1984. The discourse basis for lexical categories in universal grammar, Language 60. 703-752. 
Houston, Ann. 1989. The English gerund: syntactic change and discourse function. In Ralph W. Fasold \& Deborah Schiffrin (eds.), Language change and variation, 173-196. Amsterdam: John Benjamins.

Itkonen, Esa. 2005. Analogy as structure and process. Amsterdam: John Benjamins.

Jack, George B. 1988. The origins of the English gerund. Nowele 12. 15-75.

Jespersen, Otto. 1946. A Modern English Grammar on Historical Principles. Part V. Vol. IV: Syntax. London: Allen and Unwin

Kiparsky, Paul. 1983. Word formation and the lexicon. In Frances A. Ingeman (ed.), Proceedings of the 1982 Mid-America Linguistics Conference, University of Kansas, 3-29.

Kiparsky, Paul. 2005. Blocking and periphrasis in inflectional paradigms. In Geert Booij \& Jaap van Marle (eds.), Yearbook of Morphology 2004, 113-135. Dordrecht: Springer.

Kisbye, Torben. 1971. An historical outline of English syntax. Aarhus: Akademisk boghandel.

Kranich, Svenja. 2006. The origin of English gerundial constructions: A case of French influence?. In Andrew J. Johnston, Ferdinand von Mengden \& Stefan Thim (eds.), Language and text: Current perspectives on English and German historical linguistics and philology, 179-195. Heidelberg: Universitätsverlag Winter.

Kranich, Svenja. 2007. Some problems connected with the analysis of gerunds with direct object in Middle English. In Winfried Rudolf, Thomas Honegger \& Andrew J. Johnston (eds.), Clerks, Wives and Historians: Essays on Medieval Language and Literature, 213-233. Bern: Peter Lang.

Koptjevskaja-Tamm, Maria. 1993. Nominalizations. London: Routledge.

Langacker, Ronald W. 1987. Nouns and Verbs. Language 63(1). 53-94.

Langacker, Ronald W. 1991. Foundations of cognitive grammar 2: descriptive application. Stanford: Stanford University Press.

Langacker, Ronald W. 2008. Cognitive Grammar. A basic Introduction. Oxford: Oxford University Press.

Leech, Geoffrey, Hundt, Marianne, Mair, Christian \& Nicholas Smith. 2009. Change in Contemporary English : a grammatical study. Cambridge: Cambridge University Press.

Lees, Robert B. 1966. On a transformational analysis of compounds: a reply to Hans Marchand. Indogermanische Forschungen 71. 1-13.

Maekelberghe, Charlotte \& Liesbet Heyvaert. 2016. Indefinite nominal gerunds, or the particularization of a reified event. English Studies 97 (3). 317-340.

Malchukov, Andrej L. 2004. Nominalization, verbalization: Constraining a typology of transcategorial operations. Munich: Lincom Europa.

Malchukov, Andrej L. 2006. Constraining nominalization: function / form competition. Linguistics 44(5). 973-1009. 
McMahon, April M. S. 1994. Understanding language change. Cambridge: Cambridge University Press.

Meillet, Antoine. 1912. Linguistique historique et linguistique générale. Paris: Champion.

Miller, Gary D. 2002). Nonfinite structures in theory and change. Oxford: Oxford University Press.

Mondorf, Britta. 2011. Gender differences in English syntax. Berlin: Mouton De Gruyter.

Mourelatos, Alexander. 1978. Events, processes, and states. Linguistics and Philosophy 2(3). 415434.

Mustanoja, Tauno F. 1960. A Middle English syntax. Helsinki: Société Néophilologique.

Nevalainen, Terttu, Ramoulin-Brunberg, Helena \& Heiki Manilla. 2011. The diffusion of language change in real time: Progressive and conservative individuals and the time depth of change. Language variation \& change 23. 1-43.

Norde, Muriel. 2014. 'On parents and peers in constructional networks'. Paper presented at the CoglingDays 6, Ghent, Belgium, December 12.

Nuyts, Jan \& Pieter Byloo. 2015. Competing modals: Beyond (inter)subjectification. Diachronica 32. $34-68$.

Plag, Ingo. 1999. Morphological productivity. Structural constraints in English derivation. Berlin: Mouton de Gruyter.

Plag, Ingo 2003. Word-Formation in English. Cambridge: Cambridge University Press.

Quirk, Randalph, Greenbaum, Sidney, Leech, Geoffrey \& Jan Svartvik. 1985. A comprehensive grammar of the English language. London: Longman.

Radden, Günther \& René Dirven. 2007. Cognitive English grammar. Amsterdam: John Benjamins.

Rainer, Franz. 1988. Towards a theory of blocking: the case of Italian and German quality nouns. In Geert Booij \& Jaap Van Marle (eds.). Yearbook of Morphology 1988, 155-185. Dordrecht: Foris.

Ross, John R. 1973. Nouniness. In Osamu Fujimura (ed.), Three dimensions of Linguistic Research, 137-257. Tokyo: TEC Company Ltd.

Sanders, Gerald. 1988. Zero derivation and the overt analogon criterion. In Michael T. Hammond \& Michael P. Noonan (eds.), Theoretical Morphology, 155-175. London: Academic Press.

Smith, Carlota S. 1997. The Parameter of Aspect. Second edition. Dordrecht: Kluwer.

Sommerer, Lotte \& Elena Smirnova. 2017. Workshop proposal for the 50th Annual Meeting of the Societas Linguistica Europaea.

Swan, Michael. 2005. Practical English Usage. Oxford University Press, Oxford.

Szmrecsanyi, Benedikt. 2010. The genitive alternation in a cognitive sociolinguistics perspective. In Dirk Geeraerts, Gitte Kristiansen \& Yves Peirsman (eds.), Advances in Cognitive Sociolinguistics, 141-166. Berlin: De Guyter. 
Tajima, Matsuji. 1985. The syntactic development of the gerund in Middle English. Tokyo: Nan'un-do.

Tajima, Matsuji. 1996. The common-/objective-case subject of the gerund in Middle English. Nowele 29. 569-578.

Tajima, Matsuji. 1999. The compound gerund in Early Modern English. In Sheila Embleton, John E. Joseph \& Hans-Joseph Niederehe (eds.), The emergence of the modern language sciences: Studies on the transition from historical-comparative to structural linguistics in honour of $E$. $F$. K. Koerner, 265-276. Amsterdam: John Benjamins.

Talmy, Leonard. 1988. The relation of grammar to cognition. In Brygida Rudzka-Ostyn (ed.), Topics in Cognitive Linguistics, 165-205. Amsterdam: John Benjamins.

Taylor, John R. 1995. Linguistic categorization. Second Edition. Oxford: Clarendon Press.

Taylor, John R. 2000. Possessives in English: An exploration in Cognitive Grammar. New York: Oxford University Press.

Taylor, John R. 2004. The ecology of constructions. In Günther Radden \& Klaus-Uwe Panther (eds.), Studies in Linguistic motivation, 49-74. Berlin: Mouton De Gruyter.

Traugott, Elizabeth C. Forthcoming. Modeling language change with constructional networks.

Van de Velde, Freek. 2014. Degeneracy: the maintenance of constructional networks. In Ronny Boogaart, Timothy Colleman \& Gijsbert Rutten (eds.), The extending scope of construction grammar, 141-179. Berlin: Mouton De Gruyter.

van der Wurff, Wim. 1993. Gerunds and their objects in the Modern English period. In Jaap van Marle (ed.), Historical linguistics 1991, 363-375. Amsterdam: John Benjamins.

Vennemann, Theo. 1972. Rule Inversion. Lingua 29. 209-242.

Visser, Frederik Th. 1973. An historical syntax of the English language. Leiden: Brill.

Wurzel, Wolfgang. 1989. Inflectional morphology and naturalness. Dordrecht: Kluwer.

Zehentner, Eva. 2014. From phrase to clause(-like): On the development of present participle and verbal noun in Middle Scots. VIEWS 23, (http://anglistik.univie.ac.at/research/views/currentissues/). 